[This document contains the author's accepted manuscript. For the publisher's version, see the link in the header of this document.]

\title{
Metric Cubes in Some Music of Brahms
}

\author{
By Scott Murphy \\ Department of Music \\ University of Kansas
}

\section{Paper citation:}

Murphy, Scott. "Metric Cubes in Some Music of Brahms," Journal of Music Theory 53/1 (Spring, 2009): 1-56. DOI:10.1215/00222909-2009-020.

\begin{abstract}
:
The metric cube is a kind of graph of meters proposed as a complement to the types of metric spaces that have already been put forth in music-theoretic scholarship, particularly by Richard Cohn. Whereas Cohn's most recent kind of metric space (2001) can compare meters only if they interpret the same time span, metric cubes permit the comparison of meters that interpret different time spans. Furthermore, a metric cube posits a different kind of adjacency relation: while Cohn's most recent metric space connects two meters if their ordered pulse representations differ by only one pulse, a metric cube connects two meters if their ordered factor representations differ by only one factor. Metric cubes, and metric operations that act on the contents of a cube, reveal patterns of metric structure in three works by Brahms: the first movement of the Third Symphony op. 90, the third movement of the Second Symphony op. 73, and the last two movements of the Second String Quartet op. 51/2. These analyses also suggest correspondences in these movements between metric relationships and relationships of key, harmony, and form.
\end{abstract}


Metric Cubes in Some Music of Brahms ${ }^{\dagger}$

Scott Murphy

Richard Cohn's recent work in the area of meter has, among other accomplishments, brought meters on a more equal ontological footing with pitches, pitch classes, pitch-class collections (chords, melodies, and so forth), and many other musical "objects" that music-theoretical research has-for decades or, in some cases, centuries-compared with various kinds of relations, placed into sets, arranged into geometric spaces, or acted upon with mathematical groups. This reification of a meter as an object or "state" - more precisely, as a set of hierarchically ordered durations or pulses — admittedly belies many of its primary characteristics, particularly the dependence of its actualization upon temporal flow within a significant time $\operatorname{span}^{1}$, and the sense that it "is more an aspect of the behaviour of performers and listeners than an aspect of the music itself" (London 2001a). ${ }^{2}$ However, the benefits of reifying meters in this manner for both work-based analysis and repertoire-based theory are beginning to emerge. Contributing to work-based analysis, Cohn's two different metric spaces in turn set the stage for a metric drama in the Scherzo from Beethoven's Ninth Symphony (1992a), and facilitate analogies between metric relationships and trajectories with those in other domains in certain works of Brahms (2001). Justin London (2004, 89-99) enlists the relation of metric depth to narrate an analytical account of another movement from Beethoven, the first movement of the Fifth Symphony. Furthermore, Daphne Leong (2007) employs the four symmetries of a square to relate meters to one another in Humperdinck's Hansel und Gretel and Wagner's Parsifal, and convincingly finds that "certain metric symmetries associate with certain dramatic ones."

With regard to repertoire-based theory, I have also postulated elsewhere that a meter centrally located among all a common-practice work's meters in a certain metric space is typically the work's primary meter (Murphy 2007). However, the particular metric space that accommodates the widest 
application of this "metric-tonicization" theory to the common-practice repertoire is not one of Cohn's metric spaces, but an expanded version of one of them. This hints at the value of continuing to explore new kinds of metrical relationships, which may, in turn, facilitate significant observations of the metrical contents of a single musical work, or of the metrical contents of a musical corpus, that could form the foundation for novel analytical insights or original theories of metrical practice. The purpose of this article is to introduce and explore the analytical utility of another kind of metric space, the metric cube, which is intended to complement the types of metric relations and metric spaces that already exist, and help metric theory catch up with pitch-class set theory in terms of the diversity of ways in which its objects may be compared with one another. After reviewing Cohn's two kinds of metric space in Part I, and carving out a place among them for metric cubes in Part II, Parts III and IV analyze the third movement of the Second Symphony, and the conclusion of the Second String Quartet, respectively, using metric cubes in tandem with other metric spaces. Toward the end of the second analysis, I will suggest a less restrictive form of metric-cube space that is influenced by Leong's research, and offer an analytical observation suggestive of further research.

\section{I: Cohn's Two Metric Spaces \{A-head\}}

In his article on the Menuetto from Mozart's Symphony No. 40, Cohn (1992b) defines a metric interpretation of a time span $\mathrm{L}$, where $\mathrm{L}$ is an integer greater than 1 , as a set of pulses represented as integer factors of $\mathrm{L}$ ordered from low to high that includes 1 and L. For example, $<1,2,4,12>,<1,6$, $12\rangle$ and $\langle 1,4,6,12\rangle$ are metric interpretations of 12 . A notational demonstration of each of these metric interpretations, where the time span $\mathrm{L}$ is equal to a dotted-whole note, is provided in Example 1. As counterexamples, $<1,4,8,12>$ and $<2,3,6,12>$ are not metric interpretations; the former contains an integer that is not a factor of 12 , and the latter does not contain 1 . The number of integers in a metric 
interpretation specifies its number of levels. For example, $<1,2,4,12>$ and $<1,4,6,12>$ each has four levels, while $<1,6,12>$ has three. A metric interpretation is consonant when the division of each integer (save 1) by the integer immediately smaller than it yields an integer. For example, $<1,2,4,12>$ and $<1$, $6,12>$ are consonant, but $<1,4,6,12>$ is not, since 6 divided by 4 is not an integer. A consonant metric interpretation is fully consonant when the division of each integer (save 1) by the integer immediately smaller than it yields a prime number. For example, $<1,2,4,12>$ is fully consonant, but $<1,6,12>$ is not, since 6 divided by 1 yields 6 , which is not prime. In his research, Cohn has focused solely on fully consonant metric interpretations where the only prime-number factors between adjacent pulses are 2 and/or 3; in other words, $\mathrm{L}$ is equal to $2^{\mathrm{m}} 3^{\mathrm{n}}$, where $\mathrm{m}$ and $\mathrm{n}$ are non-negative integers. From henceforth, I will use the word "meter" to mean a fully consonant metric interpretation whose factors between adjacent pulses are 2 and/or 3 .

Another way to represent a meter is to list in order its prime-number factors such that the first factor is the length of the second pulse divided by that of the first, the second factor is the length of the third pulse divided by that of the second, and so on. For example, $<1,2,4,12>$ can be represented as [223]. This is the approach taken in Cohn's analytical study of the Scherzo of Beethoven's Ninth Symphony (1992a), with the exception of the ordering of the factors: one adopting the methodology of the Beethoven study would express $<1,2,4,12\rangle$ as [322]. In this case, the left-to-right sequence conveys an ordering of division rather than grouping, in that the 12-unit span is first divided in three equal parts, then these parts are themselves divided into two equal parts, and lastly two equal parts yet again. I will abide by both the notation of the Beethoven article-what I will call the factor representation of a meter (e.g. [322]) - and the notation of the Mozart article-what I will refer to as a pulse representation of a meter (e.g. $<1,2,4,12>$ )-despite the retrograde relationship between their orthographies. Cohn's Beethoven article also introduces the following terms: a meter whose factors are 
all 2 is considered pure duple, whereas a meter whose factors are all 3 is considered pure triple, and all other meters are mixed, in that they contain at least one factor of 2 and one factor of 3.

The metric relations that constitute what I will call Cohn's Type I metric space are few but broad: all pure duple meters are equivalent, all pure triple meters are equivalent, all mixed meters are equivalent, and each of the two sets of pure n-tuple meters is adjacent to the set of mixed meters. These relations arrange all possible meters into the three-node graph shown in Figure 1. Cohn illustrates how the metric drama of Beethoven's scherzo unfolds in this metric space; in one instance, he shows how the middle term in this three-term series - the set of mixed meters - serves as a way station between the extremes, resulting in a smooth "modulation" from pure duple to pure triple. Although this space includes any possible meter, its relatively small size proffers only three different "distance relations" between any two meters: distance of zero (i.e. equivalent), distance of one (i.e. adjacent), or distance of two (i.e. neither equivalent nor adjacent). Hence, while one may dramatize motions through this space, the range of theatrical expression is significantly limited.

Cohn's second kind of metric relation leads to what Cohn formally christened a "metric space" in his article "On Complex Hemiolas, Ski-Hill Graphs, and Metric Spaces” (2001), and what I will call Cohn's Type II metric space. First, for two meters to be what I will call commensurable - that is, to be able to be related to one another-in this Type II metric space, they must be meters interpreting the same time span. (Commensurability is not an issue in Cohn's Type I metric space, since any meter may be related to any other.) Here, it is prudent to return to the pulse representation of a meter from the Mozart article, for all commensurable meters in this Type II metric space must share two pulses: what Cohn calls the unit pulse ( 1 in the pulse representation) and the span pulse ( $\mathrm{L}$ in the pulse representation). ${ }^{3}$ For example, $<1,2,4,12>$ and $<1,2,6,12>$ are commensurable in a metric space of this second type, since both interpret a time span of 12 . This relative exclusivity immediately distinguishes it from the first metric space. Second, two commensurable meters are considered in an 
adjacency relation if their ordered pulse representations differ by only one pulse. For example, $<1,2,4$, $12>$ and $\langle 1,2,6,12>$ are adjacent, since they differ only by the third pulse: 4 in the first, 6 in the second. There are only three distinct meters that interpret a time span of $12:\langle 1,2,4,12\rangle,\langle 1,2,6,12\rangle$, and $\langle 1,3,6,12\rangle$, and Figure 2a provides the metric space they form under the adjacency as defined above. Figure $2 \mathrm{a}$ also provides the factor representation of these three meters. (The adjacency relation may also be defined on the factor representation: two meters are adjacent if the swapping of two dissimilar adjacent factors changes one of the two factor representations into the other.) Thus, Cohn's Type II metric space takes a step forward in compensating for the inability of the Type I metric space to distinguish among the many different varieties of mixed meters. Furthermore, the particular space in Figure $2 \mathrm{a}$ applies to a number of works in the common-practice repertoire: Cohn remarks that the "interplay between the three symmetrical partitions of a 12-unit span is quite common in nineteenthcentury music" $(2001,296)$.

However, as with the space in Figure 1, the space in Figure 2a conveys little information about its members relative to the entire graph and relative to one another. Relative to the entire graph, there are only two distinct locations on the graph when symmetries are factored out: the center, and the periphery. ${ }^{4}$ Between any two meters, there are only three distance relations of zero, one, and two. These may be calculated in two different ways that, in the case of Figure 2a, arrive at the same result. The first is a dissimilar-pulse distance relation. For example, $\langle 1,2,4,12\rangle$ and $\langle 1,3,6,12\rangle$ are at a distance of two under the dissimilar-pulse distance relation, since they differ by two pulses. The second is a graphtheoretic distance relation. The adjacency relation of minimal-pulse difference creates a connected graph of commensurable meters in which the graph-theoretic distance between any two meters equals the fewest number of edges (i.e. connections between vertices) that must be traversed by a path from one meter to the other. For example, $<1,2,4,12>$ and $<1,3,6,12>$ are at a distance of two under the graphtheoretic distance relation, since the shortest path between $<1,2,4,12\rangle$ and $<1,3,6,12\rangle$ in Figure 2 a 
involves two edges. Hence, Cohn's christening of the relationship between $<1,2,4,12>$ and $<1,3,6$, 12> a "double hemiola" reflects both kinds of distance relation (1992b, 13).

However, in his "Complex Hemiolas" article, Cohn observes that meters interpreting a time span of $2^{\mathrm{m}} 3^{\mathrm{n}}$ in which both $\mathrm{m}$ and $\mathrm{n}$ are greater than 1 form Type II graphs that break out of the onedimensional design of graphs like Figure 2a. For example, there are six different meters that interpret a span of $36\left(2^{2} 3^{2}\right)$. Figure $2 b$ shows the metric space these six commensurable meters form under the adjacency relation of minimal-pulse difference. Accordingly, the degree of differentiation among meters, and thus the capacity for information, in Figure $2 \mathrm{~b}$ is higher than that of Figure $2 \mathrm{a}$. Cohn also recognizes that, for graphs such as Figure $2 \mathrm{~b}$ where both $\mathrm{m}$ and $\mathrm{n}$ are greater than 1, dissimilar-pulse distance relations and graph-theoretic distance relations present different measurements in some cases. For example, the one case of divergence in Figure $2 b$ is the distance between $<1,2,4,12,36>$ and $<1,3$, $9,18,36>$, which is three in terms of dissimilar-pulse distance but four in terms of graph-theoretic distance. Cohn ultimately adopts the latter, which overall avails a slightly higher number of distance relations that may be reckoned between any two meters. ${ }^{5}$ This number (minus the relation of equivalence, or a distance of zero) equals the graph's diameter, which is the longest distance between any two vertices. For Cohn's Type II metric space, the diameter is mn. For example, in Figure $2 \mathrm{a}, \mathrm{m}=2$ and $n=1$, hence the graph's diameter is two $(2 * 1)$; in Figure $2 b, m=2$ and $n=2$, hence the graph's diameter is four $(2 * 2)$. In general, the larger $\mathrm{mn}$ is, the larger the metric space becomes, thus providing more differentiation among constituent meters. This includes more information about their distances from one another, and positions relative to the entire graph: note that, factoring out symmetries, Figure 2b has three distinct locations - central, peripheral, and in between - where Figure 2a has two. However, the larger the metric space becomes, the fewer works in the common-practice repertoire may capitalize upon its size. 


\section{Metric Cubes and Metric Operations \{A-head\}}

I imagine Cohn's two kinds of metric space at the relative extremes of a meta-space. In one corner of this meta-space is his Type I metric space, which admits any meter but distinguishes them coarsely at best. In another corner of this meta-space is his Type II metric space, which provides each meter with its own place in a potentially wide terrain but requires that every inhabitant of this terrain be of the same species. ${ }^{6}$ I propose a third metric space, dubbed a metric cube, that seeks to complement these two spaces by finding a compromise between them. (Here, "cube" is shorthand for "hypercube," a generalization of the familiar three-dimensional cube to any number of dimensions.) Meters must meet two criteria in order to be commensurable within a metric cube. First, each meter in a metric cube must have the same number of levels. (Therefore, metric cubes, like Cohn's Type II metric spaces, complement approaches such as London's "metric flux," (2004, 89-99) which relate meters to one another by the difference in the number of levels.) Yet each meter in its pulse representation need not consist entirely of integers, nor begin with 1 , nor end with the same time span as the others in the cube. (The first two liberties are cosmetic-used to provide a closer correlation between the real numbers representing pulses and the traditional fractions of American and German durational nomenclature-but the third liberty provides the true difference from Cohn's Type II metric space.) Second, all meters in a metric cube have exactly one identical pulse - the common pulse-on the same level. Numerous works from the common-practice repertoire, where at least a single pulse is maintained explicitly or implicitly throughout, meet this requirement.

As an example, the meters of $\langle 1 / 4,1 / 2,1>,<1 / 4,1 / 2,11 / 2\rangle,<1 / 4,3 / 4,11 / 2>$, and $<1 / 4,3 / 4,9 / 4>$ fully constitute a metric cube of four members, since these are the only meters that have three levels, and have the same pulse $-1 / 4-$ on the first level. ${ }^{7}$ If the common pulse of $1 / 4$ represents a notated quarter note, these four meters correspond to the time signatures of $4 / 4,3 / 2,6 / 4$, and $9 / 4$, respectively. This 
four-member cube is particularly appropriate to represent some of the metric variety in the first movement of Brahms's Third Symphony. Example 2 offers four excerpts from the exposition of this movement, each of which exhibit one of the four meters listed above. ${ }^{8}$ I have categorized each of these meters in two ways: by its association with either the first theme in the primary zone or the first theme in the secondary zone, and by its relative prominence and salience within the first category. The prevailing meter and notated time signature of the first theme in the primary zone is 6/4 (Example 2a), although it famously begins briefly with music in 3/2 (Example 2b); therefore, I will consider the former primary and the latter secondary. The first theme of the secondary zone operates mainly in 9/4 (Example 2c), but duple groupings appear intermittently, notably in m. 46 (Example 2d); therefore, I will consider the former primary and the latter secondary.

The factor representations of the members of this four-member cube, in the order they are listed in Example 2, are [23], [32], [33], and [22]. The first two meters are mixed, the third is pure triple, and the last is pure duple. In Cohn's Type II metric space, two meters form an adjacency relation if their ordered pulse representations differ by only one pulse; however, in a metric cube, two meters form an adjacency relation if their ordered factor representations differ by only one factor. In the case of this four-member cube, [22] is adjacent to both [23] and [32], and [33] is also adjacent to both [23] and [32]. These relations mold the space into the form of a square, as shown in Figure 3. In graph-theoretic parlance, a square is a 2-cube, where an n-cube is a hypercube of $\mathrm{n}$ dimensions, an n-regular graph (meaning that each vertex is connected to $n$ other vertices) of $2^{n}$ vertices and $2^{n-1} n$ edges. A metric $n$ cube contains meters of $n$ factors, and $n+1$ levels. For example, the metric 3 -cube contains the meters of [222], [223], [232], [233], [322], [323], [332], and [333], each of which represents a meter of four levels. Figure 4 provides two graphic realizations of this metric 3-cube: one planar (Figure 4a), and one drawn as a traditional cube (Figure 4b). Whereas cubes have been employed to model relations among pitchclass sets, they have not, to my knowledge, been called upon to model relations among meters. ${ }^{9}$ 
The metric cube well supplements Cohn's two metric spaces. On the one hand, a metric cube can probably admit many of a common-practice work's different meters. A considerable weakness of Cohn's second space is that it does not admit pure duple meters, which are the most frequent in the common-practice repertoire. ${ }^{10}$ On the other hand, a metric cube differentiates among many of a work's meters, which Cohn's first space does only minimally. Each meter has its own place in the cube, thus potentially resulting in a space whose size is roughly proportional to a work's metric diversity. Furthermore, mixed meters of different time spans cannot be distinguished in Cohn's first space or compared in his second, but the cube permits both of these actions.

As with Cohn's Type II metric space, one can display the constituency of metric cubes either in the form of a graph of meters or a graph of pulses. Cohn calls the graph of pulses that corresponds to his Type II metric space a "ski-hill graph," where the pulses are arranged by duple and triple factors, and the unit and span pulses serve as lower and upper boundaries of the graph, respectively. Figure 5 provides the ski-hill graph that corresponds to the metric space of Figure $2 b$, where the vertices, representing pulse durations, are displayed as numbers rather than particular notated values to correspond with the pulse notation in Figure 2b. Each of the six paths of five durations that begins with the span pulse and ends with the unit pulse corresponds to one of the six meters in Figure 2b. The graph of pulses that correspondingly displays all the meters of a metric cube is very similar to a ski-hill graph, with the exception that it pinches at one place - the common pulse - instead of two places. Figure 6a displays the graph of pulses that corresponds to the metric 2-cube of Figure 3, using the common pulse and pulse nomenclature chosen for Example 2. Each of the four paths of three durations that begins at the bottom and ends at the top corresponds to one of the four meters in Example 2. Furthermore, the pinch may occur at the top, bottom, or anywhere in between. Therefore, Figures $6 \mathrm{~b}$ and $6 \mathrm{c}$ are also pulse-graph realizations of the metric 2-cube in Figure 3, but with common pulses on different hierarchical levels. 
This flexibility allows cubes to model "bottom-up," “top-down," or "middle-out” means of organizing the metrical hierarchy. ${ }^{11}$

Returning to the Brahms analysis, the metric 2-cube of Example 3 places the two primary theme meters of [23] and [32] at opposite corners, and the two secondary theme meters of [22] and [33] also at opposite corners. Although this symmetry accords with the thematic design of Brahms's exposition, it cuts across other, perhaps more intuitive, ways of interpreting these pairs: [23] and [32] form a single (2:3) hemiola and are thus adjacent in Cohn's Type II metric space, while [22] and [33] are not commensurable in Cohn's Type II metric space and are maximally distant in his Type I metric space. Another conceptualization of the experience of hemiola may provide some assistance in illuminating this symmetry. On the one hand, the adjacency of meters in a single-hemiola relationship in Cohn's Type II metric space conveys a sense of "smoothness" through the turnover of a single pulse. We only need to re-entrain to a single different pulse; all other pulses remain locked in. On the other hand, consider the ramifications of this single-pulse change on the experience of duple and triple periodicities. During the 3/2 meter in Example 2b, the listener can experience the quarter notes as grouped into twos, and this slower grouping (which, in this case, is the tactus) as further grouped into threes. When the meter shifts to $6 / 4$ in Example 2a, the listener may experience a double transformation of these periodicities: the quarter notes are now grouped into threes, and this slower grouping (which, in this case, is still likely to be felt as the tactus) is now grouped into twos.

Where one could interpret these periodicities as simply swapping positions ("a reordering of the initial division of the bar," as Walter Frisch $(1990,156)$ characterizes the hemiola that opens Brahms's Third), one may also preserve the integrity of the position of each factor and experience a modification of both periodicities, invoking a stronger sense of alteration than if only one periodicity were changed from duple to triple, or vice versa. ${ }^{12}$ Although not hemiolic, the metric change in the secondary theme also goes through a comparable double transformation of its own: whereas Example 2c groups the 
quarter note into threes, and then this slower grouping is further grouped into threes, Example $2 \mathrm{~d}$ groups the quarter note into twos, and then this slower grouping is further grouped into twos. In the case of both thematic zones, duple periodicities both above and below the tactus are transformed into triple periodicities, or vice versa. Therefore, one may hear the unusual metric changes of the secondary theme as divulging, through a transformational likeness, a latent aspect of the primary theme's familiar hemiola.

Example 3 offers an analogy using registral harmony and voice leading that may buttress this method of interpretation, and which has some bearing on this music of Brahms in particular. Examples 3a and 3 b portray a neo-Riemannian parallel operation from an F-major triad to an F-minor triad, or vice versa. With regard to pitch content, the progression is relatively smooth, as two out of the three pitches stay put. But with regard to the two intervals between adjacent pitches as ordered in register, both intervals have been changed: each major third becomes a minor third, and each minor third becomes a major third. One mere change of note begets two changes of interval. Again, one can conceive (this time, dualistically) of these intervals as simply swapping positions, as shown in Example 3a. However, the fact that the second chord is more commonly described as a minor triad, instead of a "triad with the major third now on top," suggests the ability to keep transformational streams from crossing, as depicted in Example 3b, at least with regards to pitch relationships. This analogy maps metric pulse to registral pitch, and periodicity factor to registral intervals, particularly duple groupings to minor thirds and triple groupings to major thirds, although the reverse mapping would work as well. Therefore, the pitch equivalent to the metric relation in the secondary zone is given in Example $3 \mathrm{c}$. Whereas the quarter note served as the common pulse in the excerpts of Example 2, the note $\mathrm{F}$ below middle $\mathrm{C}$ serves as the common note in the three progressions of Example 3. The resultant progression of Example 3c is between an F augmented triad and a F diminished triad - two "pure harmonies" generated by a single interval-but can be heard in the same manner as Example 3b: each major third becomes a minor third, 
or each minor third becomes a major third. Hence, more voices may be moving, but the intervallic toggling is identical. ${ }^{13}$

Examples 3a (or 3b) and 3c both occur in Brahms's movement in a rare but pronounced dottedwhole-note harmonic rhythm, and each progression only appears in the movement to usher in the corresponding thematic zone whose primary and secondary meters it analogizes. Example $3 \mathrm{a}$ or $3 \mathrm{~b}$, the shift between F-major and F-minor triads, occurs (albeit in pitch-class space) at the outset of the first theme of the primary zone, as shown in Example 2b. (The only other foreground parallel operation in the movement-E-flat major to E-flat minor-occurs in mm. 110-11, when the first theme of the primary zone returns as part of the retransition that heralds the recapitulation.) In her exploration of narrative agendas in this symphony, Susan McClary $(1993,336-42)$ attributes this major-minor clash to the chief dilemma of the symphony's heroic, masculine protagonist, who is represented by the primary theme. Example 3c, the shift between an augmented triad and a diminished triad, only occurs in the movement (albeit enharmonically) atop the harmonic progression that immediately precedes the first theme of the secondary zone in both exposition and recapitulation; Example 4 shows its guise in the exposition, and the boxed-in area highlights the moment where Example $3 \mathrm{c}$ is most conspicuously heard. Some authors have acknowledged the similarities between Example 4 and the Sirens' music from the opening of Wagner's Tannhäuser. ${ }^{14}$ Furthermore, Hermann Krestchmar $(1890,300$; translated in Gillespie 1990, 136) referred to the secondary zone as consisting of a "group of Delilah-figures," in which the first theme (whose opening is provided in Example 2c) is "the most seductive." McClary $(1993,338)$ has picked up on these references, deliberately associating the first themes in the primary and secondary zones with both the Tannhäuser-Venus and Samson-Delilah pairs. This metrical and harmonic analysis seems to support her narrative reading. The "feminine" theme's pairing of 9/4 and 4/4, along with the striking harmonic progression enclosed in Example 4, appears on the surface to be considerably more exotic than the stock hemiolic pairing of $6 / 4$ and $3 / 2$, along with the major-minor 
shift, in the "masculine" theme. This creates an outward disconnect between the two themes, not unlike Tannhäuser's demands to be released from the Venusberg or Samson's initial thwarting of Delilah's scheming; both men ostensibly shrug their lovers off. Yet the cube analysis reveals that the mildmannered hemiola and valiant $\mathrm{P}$ transformation have a close and underhanded affinity with the alluring 9/4-4/4 pairing and the Siren-like progression than what appears at first blush, not unlike how Tannhäuser scandalizes those at the singing contest with his "Hymn to Venus" or how Samson eventually relents; both men are still inwardly and tragically tied to their corresponding temptresses.

Compared to Cohn's Type II metric space, the metric cube arguably has a higher applicability to the common-practice repertoire, as it can accommodate ubiquitous pure duple meters, and it requires one common pulse instead of two. Yet how does the metric cube match up regarding the amount of information it may relay? Here again, the metric cube serves not so much to improve upon, but to complement, metric spaces already proposed. On the one hand, the ratio of the number of graphtheoretic distance relations to the number of meters in the graph is generally lower for the metric cube. For example, the eight-meter cube in Figure $4 b$ has three non-zero graph-theoretic distance relations (a ratio of 3:8), whereas the six-meter Type II metric space in Figure $2 b$ has four (a ratio of 2:3). Moreover, a cubic graph is perfectly symmetrical; therefore, there is only one distinct location in such a space, versus the multiple distinct locations in Cohn's Type II metric spaces. However, one may orient a metric $\mathrm{n}$-cube with the pure meters on the ends, thus creating $\mathrm{n}+1$ distinct locations ordered in between the pure ends representing "degrees of mixture." This is the orientation chosen for Figure 4b, whereby the four horizontal levels on the two-dimensional page represent, from top to bottom, pure duple, two-thirds duple (or one-third triple), two-thirds triple (or one-third duple), and pure triple. (Furthermore, all of the meters of the same degree of mixture in a metric cube correspond one-to-one to all of the commensurable meters in some Type II metric space. Therefore, any Type II metric space is a subgraph of some metric cube, and any metric cube is the non-overlapping union of Type II metric spaces.) 
On the other hand, a metric cube supplies a kind of informational specificity not allowed in any of the previously discussed spaces: its distance relation can be a bijective function, or, following David Lewin's choice of parlance, an operation $(1987,3)$. A factor representation of a meter that uses only two prime-number factors is essentially an ordered string of bits, where each factor must be one of two values. ${ }^{15}$ Lewin 1995 proposed a type of operation that acts on such binary-code states: a series of 0s and $1 \mathrm{~s}$ in which a 1 toggles the bit in the corresponding position, and a 0 keeps it unchanged. With regard to a factor representation of meter, a 1 would toggle a periodicity factor from duple to triple, or vice versa. ${ }^{16}$ For example, [222] changes to [223] under the operation $<001>$ (the angle brackets are intended to set the operational label apart from the metric label). Or, to revisit the Brahms Third metric transformations, the $<11>$ transforms the primary theme's [23] and [32] meters into one another, as well as the secondary theme's [22] and [33] into one another. Figure 7 presents these relationships in the form of isographic networks. The fact that $<11>$ is a "polar" operation since all layers are toggled (or, equivalently, that both thematic zones contain "metric cube poles") signifies that both zones achieve maximal metrical variety (within the realm of duples and triples, of course) in how first the quarter note is grouped, and then how the group of quarter notes is grouped.

For an $n$-cube, there are $2^{\mathrm{n}}$ such operations, they form a direct product group of $\left(\mathrm{C}_{2}\right)^{\mathrm{n}}$, and, together with the metric states in an n-cube, they fashion an example of Lewin's Generalized Interval System $(1987,26)$. While the group structure is important, I also appreciate the fact that these toggling operations simply allow for a kind of precision unavailable in other metric spaces: that, for all meters and "intervals," there is a unique meter which lies a certain "interval" away from a given meter. ${ }^{17}$ Yet the traditional graph-theoretic distance relations on metric cubes may yield significant analytical results as well. Each of the two analyses that follow capitalize on these two kinds of metric-cube relations: many performances of the third movement of Brahms's Second Symphony feature "stepwise" distances 
between adjacent meters, and the conclusion of Brahms's Second String Quartet achieves a distinctive recurring pattern of operations as its metric content unfolds.

\section{III: Second Symphony, op. 73, iii \{A-head\}}

The first order of business in applying a metric cube to the entire third movement, Allegretto grazioso (Quasi Andantino), of Brahms's Second Symphony is deciding upon a common pulse. The movement involves tempo changes among its sections that are not uncommon in some minuet-triominuet or scherzo-trio-scherzo designs, but Brahms turns these familiar designs inside out. As Rheinhold Brinkmann explains, "it is not a triple scherzo with two trio sections but the opposite: a primary, twice repeated trio-like movement with two (non-identical) scherzo-like contrasting sections" (1995, 164). Frisch $(1996,80)$ has labeled these five sections ABA'CA', ${ }^{18}$ and Example 5 provides excerpts of the movement that outline this form, and serve as reference points for my subsequent analysis. Many scholars, perhaps David Epstein most notably, ${ }^{19}$ assert that tempo changes within a movement, or even between movements, do not necessarily have to be restraining walls for a common pulse: perhaps the composer's indication, a particular performance, or communal performance practice simply redresses the common pulse in another notational garment through the use of a simple proportional relationship between the two tempi. Initially, Brahms provided exact ratios between the movement's Allegretto (A) tempo and the tempi of both scherzo sections (B and C), each marked Presto ma non assai: going into B, the first Presto, quarter becomes half; going into C, the second Presto, quarter becomes dotted quarter. However, Brahms then asked Simrock, the publisher of the symphony, to withdraw the second ratio: "Beim zweiten Presto (3/8) steht doch nicht mehr: ${ }^{\bullet}=\uparrow^{\bullet}$. Da soll nichts stehen. [In the second Presto (3/8), this does not suit any longer: ${ }^{\bullet}={ }^{\bullet}$. Nothing should be there.]" (Brahms 1917, 79). David Epstein endorsed the ratio that Brahms omitted for multiple reasons, 
including the priming of the proportional relationship by an incessant triplet motive in the latter part of the A' section (Example 5f) whose durations and three-note stepwise descents would carry over into the C section under the ${ }^{\bullet} \cdot={ }^{\bullet}$ proportion. ${ }^{20}$ Thus Epstein's common pulse, which "never alters from section to section, though the tempo changes" $(1996,266)$, is the Allegretto's quarter note, and the tactus for the entire movement.

However, Bernard Sherman disagrees with Epstein's interpretation of tempo in this movement in particular, and uses the opportunity to reexamine the benefits of proportional tempos in general:

The advantages of proportional tempo relationships are, as Epstein has explained, that they create continuity of motion and add to the unity of a work. But this explanation emphasizes the role of tempo as a structural device. For most musicians, the choice of tempo has at least as much to do with expression as with structure. For this reason, proportions also have disadvantages. Sometimes one wants to emphasize not continuities of motion, but rather contrasts. Moreover, sometimes insisting on proportions can force one to take a tempo that does not suit the expressive character of a particular section. The latter reason may be why Brahms removed the proportional indication for the second Presto in the Allegretto of the Second Symphony - it may have felt too slow when played that way. Most conductors seem to think so, Epstein himself acknowledges it, and the score has at least one clue suggesting a faster tempo [the four measures ending C and preceding A" are labeled with "poco a poco"]. Unifying the movement's pulse may, in the end, have seemed less important to Brahms than having a suitably fast speed for the Presto. (Sherman 2003, 111)

Figure 8 provides a chart that displays the $\mathrm{A}$ and $\mathrm{C}$ tempi of sixty-six commercial recordings of the movement, plus that of one tempo recommendation in prose (Del Mar 1993, 36), which I will refer to as a "recording" in a virtual sense just for efficiency's sake. (A list of the recordings is provided in an appendix.) The $\mathrm{X}$ axis represents the metronome marking for the quarter note of the opening A tempo, the $\mathrm{Y}$ axis represents the metronome marking for the $3 / 8$ measure in the $\mathrm{C}$ section, and each point represents a pair of tempi projected by a recording. ${ }^{21}$ The lower solid diagonal line in the graph represents Epstein's recommendation that the A's quarter note equal C's dotted quarter note, and the dashed diagonal lines on either side represent a 5\% "just noticeable difference" from this proportion. The graph shows that, at least among these sixty-seven surveyed tempo pairs, none approximates 
Epstein's proportion. ${ }^{22}$ This supports Sherman's view that "many conductors seem to think" that the C section should be relatively faster than what Epstein prescribes. ${ }^{23}$

Yet a disavowal of one proportion, either by Brahms or by a consensus among conductors, does not necessarily discount other possible proportional relationships between the $\mathrm{A}$ and $\mathrm{C}$ tempi. The higher solid diagonal line in the graph of Figure 8 demarcates a 3:4 proportion between the metronome values of the quarter note in the A section and those of the dotted quarter note in the $\mathrm{C}$ section. (Again, the flanking dashed lines indicate a just noticeable difference of 5\%.) In other terms, this line represents those tempo pairs where the eighths in both B and C Prestos are equivalent, since Brahms maintained that the eighth note in the B Presto is half the duration of an Allegretto eighth note. Epstein disapproves of the 3:4 proportion as "unlikely on the grounds of musical feeling alone, not to mention other paths of logic, for the tempo of the second Presto in this case becomes something of a rush" (Epstein 1995, 536). Indeed, of the thirty-six recordings that fall outside of the $\pm 5 \%$ band surrounding the $3: 4$ proportion, twenty-six opt for a C Presto tempo that is slower than what would match a 3:4 proportion. However, twenty-nine recordings - slightly under half of those surveyed-fall within the band, and another five fall short of the band by $1 \%$. Furthermore, both the mean $(-2.1 \%)$ and the median $(-2.9 \%)$ of the ratios of the sixty-seven recordings do not exceed the $5 \%$ just noticeable difference of this tempo proportion. This general consensus suggests that one can choose absolute tempos that, as Sherman advises, "suit the expressive character" of this movement's various sections (if those conductors whose performances fall within the band are deemed capable adjudicators of such things) and achieve a proportional relationship. ${ }^{24} \mathrm{I}$ intend this survey not as an inherent criticism of Epstein's interpretation as an outlier among many other conductors' interpretations; after all, interpretations outlying a communal norm do not necessarily have less aesthetic value or merit. Rather, this survey is a means to define my analytical subject as not only Brahms's movement, but also as any one of a number of its performances (or, if the 
reader permits, an "average" performance based on the aforementioned mean or median) that clearly projects a 3:4 diminution of the tactus into the C Presto.

Using this proportion, the common pulse uniting the sections is therefore not found on the tactus level, but on a submetrical level: the duration of a sixteenth note in the A sections, or, equivalently, the duration of an eighth note in both the B and C Presto sections. Admittedly, the sixteenth-note duration appears only intermittently during the A sections: nearly all performances interpret the opening and recurrent grace notes as sixteenths, ${ }^{25}$ and the transition from the A' section into the C Presto pits dottedeighth/sixteenth rhythms directly against the eighth-note triplet rhythm that Epstein focuses upon. However, if it is allowed as the common pulse, then the second and last step is to determine the smallest cube that encapsulates as much of the movement's metric variety as possible. ${ }^{26}$ The common pulse is quite quick, and, although the B Presto bifurcates this pulse with dotted rhythms in mm. 51-54 and $\mathrm{mm}$. 57-60, it is never trifurcated. Therefore, it makes sense to treat the common pulse as the fastest common pulse in a "bottom-up" cube. A survey of the meters in the movement reveals that the music supports multiple metric hierarchies that consistently engage up to four additional levels of metric periodicity above this common pulse; therefore, a metric 4-cube is best suited. ${ }^{27}$

Figure 9 provides an overall view of the movement's metric content and the metric operations that relate adjacent meters. Columns of durational symbols and integers display five pulses within the representative meter of each of the nine passages labeled by measure numbers above and formal labels and corresponding examples below; the integers in these columns represent the number of notated measures in the pulse. A set of three short vertical lines in between two pulse values signifies a tripleratio relation between adjacent pulses; duple-ratio relations, as the unmarked of the two ratios, are therefore not displayed. This information is then summarized in the meter's factor representation. For example, reading the [2322] label of the opening A section left-to-right corresponds to reading the column below it top-to-down: not triple, triple, not triple, not triple. The hairpins indicate which pulses 
change, and if they increase or decrease in duration, in a metric-state progression. The bottom (quickest) level of pulses is easily seen as the common pulse, since it is the only level without hairpins. By displaying each pulse, the original notated durations are preserved, yet the horizontal alignment automatically performs the notational conversion into and out of the B and C Prestos. The operations on top of the figure track the toggling of ratios.

Of the sixteen possible meters in this metric cube, this movement employs five: one that is pure duple ([2222]), three that are three-fourths duple ([2322], [3222], and [2223]), and one that is equal parts duple and triple ([2323]). In Figure 9, these different degrees of mixture are displayed by vertical height comparable to Figure 4b. These five different 4-cube meters account for nearly all of the movement's metric content. ${ }^{28}$ The operations that describe metric successions into and within both B and C Prestos are all "stepwise," in that each operation contains a single 1, signifying that only one factor in the metric hierarchy is toggled at a time. Moreover, the metric changes initially within each of the Presto sections ([2222] to [3222] in B, and [2323] to [2223] in C) are similar, in that both return the meter to a degree of mixture equivalent to, but with a hierarchical distribution different from, that of the A sections' [2322]. Skewed triangles highlight these corresponding metric progressions in Figure 9.

Therefore, a 3:4 proportion generates multiple stepwise metric-cube transitions in the movement and correspondences between metric progression and formal design, offering impressions of both continuity and unity that Epstein values, but from a different perspective. However, as this perspective is probably less familiar and perhaps less intuitive, closer examinations of the first $(A \rightarrow B)$ and sixth $\left(A^{\prime} \rightarrow C\right)$ metric transitions may help to communicate the narrative of "smoothness." Each of the A sections is best represented by [2322], the meter that groups 3/4 Allegretto measures in twos, although two-measure groups do not conspicuously persist throughout the entirety of the A sections. When the B section begins, the triple factor between the Allegretto's beat and measure levels toggles to duple, and the music becomes pure duple. Recall that the single hemiola's alteration of a single pulse duration 
changes two periodicity factors; somewhat dually, a toggling of a single factor may, via a "ripple effect," change two or more pulse durations. Such is the case here, as a stepwise operation replaces both the Allegretto's dotted-half (metric) and dotted-whole (hypermetric) pulses with their undotted counterparts (two-measure and four-measure periodicities in the B Presto notation)-this double replacement is illustrated in Figure 9 with two hairpins between the first two columns. Yet my sense of this metric transition (with the shift to a constant eighth-note pulse aside) is less one of overhaul and more one of ease, and this sense is captured better with the single factor turnover than the double pulse turnover.

Since the single toggle from $\mathrm{A}^{\prime}$ to $\mathrm{C}$ is submetrical, the ripple effect is more pronounced, as all of the pulses in the hierarchy, save the common pulse, are replaced by new pulses: note the four hairpins in between the A' and C columns in Figure 9. However, the "intervallic" structure of the meter largely remains intact. This can be most easily experienced if the C Presto tactus pulse is three-halves, rather than three-fourths, the duration of the Allegretto tactus pulse. (Particularly when using the "average" Allegretto tempo of $\_=90$, the C Presto tactus tempos of $\iota_{.}=120$ and $\iota_{.}=60$ are equally plausible.) This would group two C Presto measures into a single, slower beat, and would result in a duple division below the beat, and, if the beat is conceived of as a quarter-note duration, 3/4 measures grouped in twos above the beat, which is exactly the metrical hierarchy that surrounds the beat in the Allegretto. The only difference between the two meters is the submetrical level below the duple division of the beat. ${ }^{29}$ The sensation that the $\mathrm{C}$ Presto is a slower version of the same meter found in the A sections is supported by two 3:2 pitch expansions of Allegretto material to begin the C Presto, both shown in Example 6. First, the highest note in each of five notated two-measure groups starting in m. 132 duplicates the first five notes of the Allegretto theme after a 3:2 reduction. Second, mm. 126-31 function as a hypermetric anacrusis to the $\mathrm{C}$ section, since changes of key and orchestration dictate that the duple grouping at the highest level of the [2323] hierarchy best fits $\mathrm{mm}$. 132-55. (This is the reason for the omission of $\mathrm{mm}$. 
126-31 from Figure 9.) The descent D-C-B-A, emphasized by accents, matches a 3:2 expansion of the D-C-B-A eighth-note descent in the A section; in terms of the C Presto's "slower 3/4," both also begin on downbeats in the triple beat groupings and in weak hypermeasures in the duple measure groupings.

Epstein argued that the metric transitions in this movement using his preferred 1:1 ratio are "natural" and "comfortable," ${ }^{30}$ whereas he shunned the 3:4 proportion as lacking such properties. On the one hand, my analysis above suggests how, from a metric-cube vantage point, a 3:4-proportioned performance may also achieve a smooth and internally consistent flow from one meter to the next. On the other hand, the change of tactus that all of the surveyed conductors summon when entering the $\mathrm{C}$ Presto produces a palpable, undeniable contrast with what came before; in these terms, the C Presto operates on a different plane from that of the B Presto, which continues the Allegretto tactus. London has argued convincingly how alterations of the tactus are more conspicuous than alterations of other pulses. This sense of contrast resonates to some degree with Sherman's notion, quoted earlier, that "sometimes one wants to emphasize not continuities of motion, but rather contrasts." However, in making this statement in the context of the disadvantages of tempo proportions, Sherman implies that tempo proportions and expressive contrasts are mutually exclusive. As way of an analogy, the relationship between two pitches or two tonal centers may be measured precisely yet still heard as contrasting. For example, interpreters of the tonal plan of this G-major movement have found certain key choices to be decidedly unusual: Knapp considers the A-major key in the opening of the C Presto (mm. 132-55) as "wrong," 31 and Brinkmann (as one of many) hears the F\{sharp\}-major key in the opening of the A" section as "striking."32 Tovey $(1981,206-7)$ interprets these keys as "the most unorthodox possible" and "remote," respectively. These interpretations follow, at least in part, from the atypical stepwise key relationships to the movement's tonic, instead of more customary fifth or third relations, as well as the fact that material first presented in tonic is being transposed further away from tonic when it is restated later in the movement. Metric theory may not be as advanced as tonal theory in 
specifying common-practice conventions and contraventions, but, in lieu of this, a 3:4-proportioned performance of this movement establishes two significant metric contrasts that are analogous to, and thereby glean some of their features from, these two tonal contrasts. ${ }^{33}$

As shown in Figure 9, three meters in the movement are mixed one-fourth triple and threefourths duple: the [2322] of the A sections, the B Presto's [3222], and the C Presto's [2223]. Therefore, they may be arranged in a Cohn Type II metric space where $m=1$ and $n=3$, and the span pulse is 24 times $\left(3^{1} 2^{3}\right)$ the duration of the unit pulse. However, in another article (Murphy 2007, 338-39), I have generalized this type of space further by arranging the meters into a linear pattern based on duple relations among their characteristic "triple-count" frequencies. This allows nearly all of the entire C section to be represented by the triple-count relation between the Presto's notated eighth note and dotted quarter (or, equivalently, between the Allegretto's notated sixteenth note and dotted eighth). Figure 10a arranges these three triple-count frequencies into a linear graph using a duple-factor adjacency relation: the notated values refer to the Allegretto notation, and not to the Presto conversion. The A theme's triple-count, established by the movement's form as the characteristic triple-count of the movement's most primary or representative meter (the Allegretto's 3/4), is centrally located in Figure 10a. ${ }^{34}$ However, its centrality is asymmetrical: the C Presto's triple count is four times as quick as the tonic triple count. Moreover, the triple-count pulse that would fill the gap in between-within either a bit of 6/8 in the A sections or a bit of notated 3/4 in the C Presto-is entirely absent in the movement, as represented by the blank vertex. Therefore, the double hemiola, compounded by the conspicuous lacuna, isolates the C Presto's meter. Following Lewin and Cohn, who analogize such linear distributions of meters with segments of perfect fifths, the asymmetrical metric graph of Figure 10a neatly matches the asymmetrical graph of keys in Figure 10b, both in graphic form as well as synchrony between the meters and keys during the movement. ${ }^{35}$ The move to [3222] and its half-as-fast triple count in $\mathrm{m} .51$ of the B Presto coincides with the move to the key of $\mathrm{C}$ major; both the subdominant shift and single hemiola 
with the A's [2322] ruffle few feathers. ${ }^{36}$ The sudden lurch to the four-times-as-fast of a triple count to start the C Presto, and the unprepared shift to the "wrong” key of A major six measures later correspond analogously. ${ }^{37}$ Furthermore, the key of A major does not function as double dominant leading to the key of D major, nor is this dominant key ever assigned a theme or tonicized for longer than a couple of measures during the entire movement; hence the blank vertex in Figure 10b, and the further estrangement and "wrongness" of A major.

The contrast of the F\{sharp\}-major key in the A" section (m. 194ff.) plays out somewhat differently than the contrast of the A-major key in the C Presto (m. 132ff.), although each tonicized pitch is a single diatonic step from the movement's tonic of G. First, the transposition relatively far from tonic, and relatively late in the movement, of primary material that has already been heard multiple times in tonic alludes to a similar practice in some Classical rondos and sonata-rondos of Mozart and Beethoven. ${ }^{38}$ But a semitonal transposition in particular augments a curious paradox: the key is at once considerably distant, if gauging tonal distance by perfect fifths and/or thirds, and maximally proximal, if gauging distance by semitones. ${ }^{39}$ The latter measure, abetted by no change in mode, permits the semitonal transposition to be interpreted as a substitute, even while the former measure creates a suspicious, mysterious, or magical aura around the surrogate. ${ }^{40}$ Performances that create a 3:4 tempo proportion conjure a similar paradox in duration-space right before the $\mathrm{F}\{$ sharp $\}$-major substitution. Example 7 reproduces $\mathrm{mm}$. 172-95, the bulk of which provides the retransition from the end of the C Presto to the A" section. Starting in m. 180, the meter begins to support a notated quarter-note pulse through the close imitation of the C-B-A-E motive among the strings, and even a notated half-note pulse through this motive's descending octave transpositions. This gives the impression of another metric retransition highly comparable to the one that prepared the Allegretto's [2322] meter at the end of the B Presto (mm. 101-6, Example 5e), although this one requires a double toggle or, equivalently, a double hemiola. An analogous tonal retransition certainly appears possible, even probable, as the A-minor 
chord of mm. 176-79 could easily function as a harmonic pivot from the E-minor tonicization in $\mathrm{mm}$. 172-75 back to $\mathrm{G}$ major, just as the same music served to return the B Presto to the key of G major in mm. 87-88. Example 8 offers a recomposition that sees both metric and tonal retransitions through to a normative G-major return of the initial Allegretto theme.

However, once m. 188 arrives, neither of these apparent retransitions follows through in such a conventional manner: the tonal center swerves from the brink of $\mathrm{G}$ back toward $\mathrm{E}$, if only temporarily, and the groupings of notated eighth notes swerve from the brink of twos and fours back toward threes, if only temporarily. (The harmonic shift is not quite as abrupt as the metric shift: savvy listeners will probably interpret the $\mathrm{F}$ \{sharp\}-half-diminished chord in $\mathrm{mm}$. 184-87 to be more likely as predominant in $\mathrm{E}$ and less likely as dominant substitute in G.) As shown with the parenthetical tempo indications in Example 7, a typical 3:4-proportioned performance keeps the eighth note at the same value into m. 188, equates the dotted-quarter duration to the quarter duration into m. 190, and gradually (poco a poco) decreases the tempo in some manner during mm. 190-93 before A"' and its Tempo primo arrive in m. 194. This means that the repeated top-voice Bs in mm. 188-89, clearly anticipating the initial A theme, are 4/3 faster than their Allegretto-paced counterparts. Likewise, before any rallentando, the notated eighth notes in mm. 190-91 are 4/3 faster than the eighth notes of the Allegretto tempo, presented as usual by the 'cellos in m. 194ff. This is the one moment in the movement where single-bowed staccato eighth notes can be as crisp as the 'cellos' pizzicato notes; the upper strings in many performances of mm. 190-91 seem to anticipate, with clearly detached articulation, the 'cellos' plucking of mm. 190-191. Both of these connections can create the impression that the A theme, including its various metric levels, is beginning to return, but it is just a bit too fast, analogous to the fact that $\mathrm{F}$ \{sharp\} major is just a bit too low, thus invoking a similar paradox in the metrical realm. Of course, a C Presto tempo slower than that of a 3:4-proportioned performance (but faster than Epstein's recommendation) can still achieve this same close-but-not-quite experience, and even make the analogy tighter, if one wants to fret about the 
precise numerical ratio between the referential frequency and its substitute. However, I prefer the 3:4proportioned performance, in that the sensations of both paradoxes can be precisely measured with two familiar intervals and therefore experienced in relative terms: just as the mediant of $\mathrm{G}$ becomes the subdominant of F\{sharp\} in mm. 188-94, the duration of one-half of an Allegretto eighth note (the $\bullet \rightarrow$ conversion at m. 33 and the equivalence of the Prestos' eighth notes) becomes two-thirds of an eighth note in mm. 190-91 (the..$\rightarrow$ conversion at m. 190). In Epstein's interpretation, m. 190 restores the Allegretto tempo exactly, just as the previous retransition did at the end of the B Presto, and no rallentando (even poco a poco) is required. While I appreciate the neatness of Epstein's retransition, I prefer a performance of this retransition in which pitch and time seem to collude with one another in creating contrast and novelty.

\section{String Quartet No. 2, op. 51/2, iv \{A-head\}}

There is one clear choice for this finale's common pulse, at least before the slight but nonetheless significant tempo changes of the coda: eighth notes permeate at least two-thirds of its measures, and all other durations in the movement are multiples of the eighth note. The smallest cube that best captures the wealth of metric variety in this movement is a "bottom-up" 3-cube with the eighth note as the common, and fastest, pulse. Brahms uses six of the eight meters in this 3-cube at least once in the movement, and all six appear during the 100-measure sonata-form exposition. In other words, this exposition explores six of the eight possible ways, within binary and ternary means of metric organization, to group eighth notes, to group this group, and then to group this group of groups. This degree of metric diversity, as quantified by how much of a metric 3-cube is utilized, is rather unusual among Brahms's sonata-form expositions. However, similar to a metric/tonal tradeoff Cohn recognizes in Brahms's "Von ewiger Liebe" $(2001,312)$ and Carl Schachter notes in a passage from the first 
movement of Brahms's Second Symphony (1983, 60; cited in Cohn 2001, 312-13), this diversity may be interpreted as compensation in the metric realm for one of Brahms's most tonally conservative of expositions. The primary theme (mm. 1-37) is firmly grounded in A minor, the eight-measure transition (mm. 37-44) makes a beeline for the dominant of $\mathrm{C}$ major, and the secondary theme group (mm. 44-100) hardly wavers in its support of the key of C major, which is reinforced by "three cadential closes," as Arnold Whittall $(1987,159)$ hears it. Here, the exposition's metrical scheme and key scheme do not collude with one another but instead complement one another with regards to the complexity of their content.

Figure 11 arranges these six meters in the order in which they first appear in the movement, and Example 9 provides scores of most of the corresponding measures that convey these meters. ${ }^{41}$ Since the first two meters partially overlap, their ordering is determined by when all of the pulse durations have fully transpired: the [322] (3/2 meter + eighths) of the first violin is finished by the end of $\mathrm{m} .2$, whereas the [332] (9/4 meter + eighths) of the other three instruments does not wrap up until the end of m. 3. (Unlike those in the Second Symphony analysis, the slowest pulses of two of the meters in Figure 11[322] and [323] - are not periodic. However, I will still treat them as four-level meters, given the clear delimitations of these slowest pulses by the music that surrounds them.) Like Figure 9, the horizontal position of a meter's label represents its degree of mixture. Figure 11 reveals a pattern in the chronology of the introduction of new meters. In general, the operations oscillate between stepwise $(<100>$ or $<010>$ ) and polar $(<111>)$ metric distances; more particularly, the operations form a palindrome. The stepwise distances associate two meters that are already bundled together somehow: in the case of the first two pairs, by immediate succession or simultaneity; in the case of the last pair, through clearest association with themes that frame the second part of Brahms's two-part exposition. The first two stepwise toggles can be readily heard as expansions. First, the descending arpeggiation through an Aminor chord on the half-note third level of [322] in the first violin's first two measures is inverted and 
augmented by 3:2 on the dotted-half-note third level of [332] in the cello's first three measures. Second, the first violin's [223] in mm. 9-12 seamlessly transforms into a stretched-out [323] accompaniment that conforms to a return of three-bar phrasing in mm. 13-15. As with the succession of meters in the symphonic movement examined earlier, the succession of new meters in this finale's exposition alters the degree of mixture incrementally, depicted by the gentle rises and falls of the metric labels' horizontal positions in Figure 11.

Two meters in this 3-cube are missing: the pure triple [333] is predictably absent, and the movement also lacks [233]. However, in music of the previous movement (Quasi minuetto, moderato), “all the groupings are by threes," as Daniel Gregory Mason $(1933,104)$ describes it. This minuet both begins and ends with the same music in small-ternary form. Taken from the end of the movement, Example 10 displays the six measures that begin this small ternary's exposition and the nine measures that begin its contrasting middle. If the triplet eighth is treated as the fastest and common pulse in a 3cube, then mm. 134-9 articulate a [333] meter and, owing to the pacing of the descending bass tetrachord and the exact repetition within mm. 153-5 that contravenes the prevailing [333], mm. 152-57 compresses the meter to [233].

Although these are the two missing 3-cube meters from the finale, how might these two thirdmovement meters be related to the six of the finale? One solution is to apply Leong's concept of "metric shapes" to metric cubes. Leong's model "expands the metric states that can be considered" (2007, forthcoming) by removing the restrictions that two meters, in order to be related to one another, need to 1) share two pulses (Cohn's unit and span pulse), or even one pulse (my common pulse), and 2) be fully consonant. However, it should be noted that her second slackening offers more of an expansion than the first, since all three approaches (Cohn's, mine, and Leong's) set requirements of comparable stringency for commensurability among fully consonant meters. For Cohn and myself, meters are commensurable if they have one or two shared pulses with limits on which levels those shared pulses 
reside; for Leong, meters are commensurable if they have the same shape as visualized upon a form of a ski-hill graph extended without boundaries. She proposes four relations among commensurable meters that correspond to four symmetries of a square: identity, rotation by $180^{\circ}$, vertical reflection, and horizontal reflection. Alongside Leong's symmetry relations, I propose adding "toggling relations" that specify a relationship between two fully consonant meters with the same number of levels. For example, the [233] of mm. 152-57 in the third movement and the [322] of the first violin's first two measures in the finale would be related by the toggling relation $<111>$, regardless of the tempo of these meters and the number of shared pulses. Admittedly, toggling relations require fully consonant meters, whereas Leong's symmetry relations do not, but the trade-off seems worth it: toggling relations make commensurable any two fully consonant meters with the same number of levels. Figure 12 displays the toggling relations between adjacent meters (again, ordered by their initial appearances) in the small ternary that ends the third movement and the sonata-form exposition that begins the finale. Not only are the third movement's [333] and [233] the two 3-cube meters missing from the finale, but they also anticipate the same pattern of alternating stepwise and polar relations among the first appearances of meters in the finale's exposition. Furthermore, the sequence of seven relations among the eight meters begins and ends with the same series: $<100>,<111>,<010\rangle$. (Note, however, that the highest turnover of pulses from one new meter to the next - the vertical stack of three hairpins in Figure 12-occurs only between the movements.)

Another solution does not require invoking the greater generality but less precision of toggling relations: the eight meters of Figure 12 could be commensurable within the proposed 3-cube if the common pulse of the two third movement meters - the triplet eighth note-equals the common pulse of the six finale meters - the eighth note. Although many performances opt for a finale tempo that sets its eighth note appreciably shorter in duration than that of the third movement's triplet eighth note, commercial recordings from at least four quartets (Vertavo, Verdi, Melos, Alban Berg) achieve this 
equivalence within a just noticeable difference of 5\%, and two others (Colorado and Cleveland) exceed this range by no more than $1 \%$. Not only do the toggling relations of Figure 12 become toggling operations under this proportion, thereby increasing the distinctiveness of the sequence of meters, but the common pulse also permits the metaphorical motions through metric space between the two movements to be more precisely gauged. The first violin's three eighth notes in the finale's pivotal pickup measure facilitate this connection: their stepwise anacrustic ascent atop the treble-clef staff harkens back to similar motives from the main theme of the Menuetto, especially when the performer gives them equal weight instead of augmenting the bowing of up-down-up-(then down on the first downbeat) with stresses on the downbows. This allows the triple grouping of the common pulse to function as a brief but nonetheless salient reference to the meters of the previous movement; this grouping is then transformed and recontextualized as the finale gets underway. Such a reference is analogous to how Brahms begins a number of the finales of his multi-movement instrumental works with a short but clear reference to the concluding key of the penultimate movement, thus signposting the path blazed by the two movements through tonal space. ${ }^{42}$ However, in the case of op. 51/2, both the penultimate and final movements are in the same key and mode; this tonal and modal redundancy between successive movements is considerably less common in Brahms's multi-movement instrumental works than in comparable Classical-era works. ${ }^{43}$ Once again, the considerable variety of meters within the confines of a metric 3cube may be interpreted to compensate for an atypical restraint of tonal Wanderlust; earlier, the compensation was within a movement, but here it involves two successive movements.

Each of these solutions has its strengths and weaknesses: for example, although toggling operations provide a higher degree of distinctiveness than that afforded by the Leong-inspired toggling relations, such relations are not confined to a particular tempo relation between movements. And this is how it should be: I speculate that the more complementary perspectives that metric theory invites and accommodates, the better it will be able to reveal trends among repertoires, offer unique hermeneutic 
insights, model musical perceptions, and expand musical conceptions. To demonstrate the need for more perspectives, I offer one final analytical point on the finale of op. 51/2 that appropriates aspects from both Cohn's ski-hill graphs and my metric cubes, and yet requires a space for its observations that falls short of either of them. It begins with the observation that the form of this finale follows a rotational design, provided in tabular form in Figure 13, that incorporates both sonata and rondo components. ${ }^{44}$ Rotations 1 and 3 resemble textbook instances of a sonata-form exposition and recapitulation. Rotation 2, however, begins more like a second exposition rather than a development, as it presents both another statement of the primary theme group in A minor and another statement of the first module $\left(S^{1.1}\right)$ of the secondary theme group, which, although in $\mathrm{F}$ major instead of $\mathrm{C}$ major, is kept intact and not altered as one might expect in a P-S developmental rotation. Only after this second statement of $\mathrm{S}^{1.1}$ does the music begin to behave in a developmental fashion, subjecting $S^{1.2}$ to sequential activity characteristic of what William Caplin (following Erwin Ratz) calls a "core” (1998, 141-47). Thus, the first two rotations present $S^{1.1}$ initially in secondary keys of $\mathrm{C}$ and $\mathrm{F}$, which symmetrically frame the main key of A to which $\mathrm{S}^{1.1}$ is transposed during its third appearance in the third rotation.

Yet, just as $\mathrm{S}^{1.1}$ finds its way to $\mathrm{P}^{1}$ 's one and only key (the movement's tonic key of $\mathrm{A}$ ) toward the end of the movement, $\mathrm{P}^{1}$ finds its way to $\mathrm{S}^{1.1}$ 's one and only meter (the movement's "tonic meter" of duply-grouped $3 / 4$ measures) toward the end of the movement ${ }^{45}$ furthermore, as with the tonal journey of $\mathrm{S}^{1.1}$, the metric journey of $\mathrm{P}^{1}$ involves two way stations that are symmetrically positioned around the eventual destination. Figure 14 a provides a graph of pulses that are germane to $\mathrm{S}^{1.1}$, $\mathrm{s}$ metric transformations, and Figure 14b provides an analogous graph of diatonic pitch classes. The path on the right side of Figure 14a-the meter with the pulses quarter, half and dotted whole-represents the meter of $\mathrm{P}^{1}$ 's first two bars in the melody of the first violin. The left path-the meter with the pulses quarter, dotted half, and three dotted halves - represents the three-bar phrasing of $\mathrm{P}^{1}$ s accompaniment in the first 
rotation. The middle path - the meter with the pulses quarter, dotted half, and dotted whole-is $\mathrm{S}^{1.1}$, $\mathrm{S}$ meter throughout the movement.

In the first rotation, both of these flanking meters are present within $\mathrm{P}^{1}$. In the second rotation, $\mathrm{P}^{1}$ trades its distinctive three-bar phrases for four-bar phrases, thus replacing the three-dotted-halves pulse with the dotted-whole pulse (as shown in Figure 14a by the pulse exchange $\alpha$ ), as four-measure groups also convey two-measure groups. Although this brings $\mathrm{P}^{1}$ s $\mathrm{s}$ meter closer to that of $\mathrm{S}^{1.1}$, it still includes the distinctive hemiola and its half-note pulse. In the third rotation, $\mathrm{P}^{1}$ returns to three-bar phrases. Yet $\mathrm{P}^{1}$ 's accompaniment changes from plain chordal trochees to a compression of $\mathrm{P}^{1}$, $\mathrm{s}$ first five notes that works as a new bass line in counterpoint with the original $\mathrm{P}^{1}$. This suggests a way for $\mathrm{P}^{1}$ to maintain the "sawtooth" contour characteristic of the theme while converting its half note pulse to a dotted-half pulse (as shown by the pulse exchange $\beta$ in Figure 14a). The final statement of $\mathrm{P}^{1}$ at the end of the fourth rotation employs both of these exchanges: the first violin co-opts and then further continues the compression of $\mathrm{P}^{1}$ first suggested by the bass line in the beginning of the third rotation, thus putting $\mathrm{P}^{1}$ into an uncontested 3/4 meter for the first time in the movement, and the measures are also grouped in twos and fours. Therefore, just as $S^{1.1}$ was first presented in the movement's mediant and submediant keys (the left and right paths of Figure 14b) before arriving in the centrally located tonic key (where $\mathrm{P}^{1}$ has been all along, represented by the middle path of Figure $14 \mathrm{~b}$ ), $\mathrm{P}^{1}$ first adopts flanking meters (the left and right paths in Figure 14a) before arriving in the centrally located meter (where $\mathrm{S}^{1.1}$ has been all along, represented by the middle path of Figure 14a). $\mathrm{P}^{1}$ 's metric journey is summarized in Example 11.

Furthermore, this transformation of $\mathrm{P}^{1}$ in the movement's coda brings this theme closer not only to $S^{1.1}$, s meter, but also to $S^{1.1}$, s melodic shape. To be sure, the initial presentations of $\mathrm{P}^{1}$ and $\mathrm{S}^{1.1}$ bear a hidden similarity: a pitch-to-rhythm reduction in the style of Maury Yeston (1976, $4 \mathrm{ff}$.$) reveals that$ $\mathrm{S}^{1.1}$ s chord tones outline a descending triadic arpeggiation in half notes that resembles the same descending triadic arpeggiation in $\mathrm{P}^{1}$, as shown in Example 12a. However, the compressed version of $\mathrm{P}^{1}$ 
in the coda bears even a stronger similarity of contour to $S^{1.1}$ over more measures, as proposed in Example 12b.

On the one hand, Figure 14a is not quite a ski-hill graph: the pulse that would make it so, a spanpulse duration equal to three dotted whole notes, is not offered by $\mathrm{S}^{1.1}$ nor by some instances of $\mathrm{P}^{1}$. Therefore, in trying to model this relationship using existing metric approaches, pulse exchange $\alpha$ is perhaps better understood as a "stepwise toggle"-exchanging a triple grouping of the dotted half note for its duple grouping - rather than as a single hemiola. On the other hand, a "stepwise toggle" cannot represent pulse exchange $\beta$. Although, by adding a whole-note pulse, Figure 14a would contain all the pulses of a "bottom-up" 2-cube with the quarter note as the common pulse, pulse exchange $\beta$ still covers a distance of two in the cube, but only a distance of one-a single hemiola-in Cohn's Type II metric space. And yet the symmetrical flanking is unambiguous: as the opening measures of $\mathrm{P}^{1}$ 's melody progress through the movement, its hypermetric pulse decreases by a factor of 3:2 (from three-measure phrases to two-measure phrases), and its tactus pulse increases by a factor of 3:2 (from the half note to the dotted half note), thus matching $\mathrm{S}^{1.1}$ 's meter. While metric cubes and Cohn's metric spaces cannot quite offer an environment in which this symmetry is transparent, perhaps another metric geometry can. This, however, becomes the topic of another paper. 


\section{APPENDIX}

\begin{tabular}{|c|c|c|c|c|c|c|}
\hline Orchestra & Conductor & Year & $\mathrm{A} \cdot=$ & $\mathrm{C}_{.} .=$ & $\begin{array}{l}\% \Delta 4 / 3 \mathrm{~A} \\
\text { and } \mathrm{C}\end{array}$ & $\begin{array}{l}\% \Delta \mathrm{A} \\
\text { and } \mathrm{C} \\
\text { (Epstein) }\end{array}$ \\
\hline $\mathrm{BBC}$ & Be`lohlávek & 1998 & 104 & 119 & -16.8 & 12.4 \\
\hline Suisse Romande & Ansermet & 1963 & 93 & 106 & -16.7 & 12.5 \\
\hline Seito Kinen & Ozawa & 1991 & 98 & 114 & -13.7 & 14.7 \\
\hline Staatskapelle Dresden & Sanderling & 1972 & 90 & 106 & -13.5 & 14.9 \\
\hline Royal Phil & Judd & 1994 & 94 & 113 & -11.5 & 16.3 \\
\hline National Bordeaux Aquitaine & Lombard & 1990 & 93 & 112 & -10.4 & 17.2 \\
\hline Philharmonia of London & Klemperer & 1958 & 89 & 107 & -10.3 & 17.3 \\
\hline Los Angeles Phil & Guilini & 1981 & 89 & 107 & -10.2 & 17.3 \\
\hline New York Phil & Masur & 1992 & 95 & 115 & -10.2 & 17.4 \\
\hline Vienna & Monteux & 1963 & 97 & 117 & -9.7 & 17.8 \\
\hline London Phil & Alsop & 2005 & 94 & 115 & -9.6 & 17.8 \\
\hline London & Haitink & 2003 & 93 & 113 & -9.4 & 17.9 \\
\hline San Francisco & Monteux & 1951 & 96 & 117 & -9.1 & 18.2 \\
\hline San Francisco & Monteux & 1945 & 101 & 124 & -8.6 & 18.5 \\
\hline Academy of St. Martin in the Fields & Marriner & 1998 & 99 & 121 & -8.5 & 18.6 \\
\hline Philadelphia & Muti & 1988 & 93 & 115 & -7.6 & 19.3 \\
\hline Cleveland & Ashkenazy & 1990 & 93 & 115 & -7.6 & 19.3 \\
\hline Israel Phil & Mehta & 1992 & 95 & 118 & -7.0 & 19.7 \\
\hline Amsterdam Concertgebouw & Beinum & 1955 & 94 & 118 & -6.2 & 20.3 \\
\hline Berlin & Karajan & 1986 & 90 & 113 & -6.2 & 20.3 \\
\hline Vienna & Kertész & 1965 & 98 & 123 & -6.0 & 20.5 \\
\hline Berlin & Böhm & 1950 & 85 & 107 & -5.6 & 20.8 \\
\hline Danish Radio & Horenstein & 1972 & 92 & 116 & -5.5 & 20.9 \\
\hline Stuttgart Radio & Celibidache & 1975 & 93 & 117 & -5.4 & 21.0 \\
\hline London Classical Players & Norrington & 1993 & 103 & 131 & -5.4 & 21.0 \\
\hline Chicago & Barenboim & 1993 & 89 & 113 & -5.3 & 21.0 \\
\hline \multicolumn{2}{|l|}{ Del Mar } & 1993 & 88 & 112 & -4.8 & 21.4 \\
\hline London & Järvi & 1988 & 90 & 115 & -4.6 & 21.5 \\
\hline Scottish Chamber & Mackerras & 1997 & 100 & 128 & -4.4 & 21.7 \\
\hline Berlin & Abbado & 1988 & 89 & 114 & -4.4 & 21.7 \\
\hline Philadelphia & Ormandy & 1966 & 87 & 111 & -4.2 & 21.9 \\
\hline Utah & Abravanel & 1977 & 90 & 115 & -3.8 & 22.2 \\
\hline Royal Concertgebouw & Chailly & 1989 & 93 & 120 & -3.1 & 22.7 \\
\hline Cleveland & Szell & 1967 & 89 & 115 & -2.9 & 22.8 \\
\hline Royal Phil & Pesek & 1992 & 91 & 119 & -1.7 & 23.7 \\
\hline Berlin & Karajan & 1978 & 94 & 123 & -1.4 & 24.0 \\
\hline Boston & Munch & 1956 & 99 & 130 & -1.3 & 24.0 \\
\hline London Phil & Sawallisch & 1999 & 92 & 121 & -1.2 & 24.1 \\
\hline Boston & Leinsdorf & 1965 & 85 & 112 & -0.9 & 24.3 \\
\hline Mexico City Phil & Lozano & 1994 & 89 & 118 & -0.8 & 24.4 \\
\hline Pittsburgh & Steinberg & 1963 & 103 & 136 & -0.7 & 24.4 \\
\hline Berlin & Harnoncourt & 1997 & 87 & 115 & -0.6 & 24.6 \\
\hline
\end{tabular}


APPENDIX (continued)

\begin{tabular}{|c|c|c|c|c|c|c|}
\hline Orchestra & Conductor & Year & $A \cdot=$ & $\mathrm{C}_{.} .=$ & $\begin{array}{l}\% \Delta 4 / 3 \mathrm{~A} \\
\text { and } \mathrm{C}\end{array}$ & $\begin{array}{l}\% \Delta \mathrm{A} \\
\text { and } \mathrm{C} \\
\text { (Epstein) }\end{array}$ \\
\hline Milwaukee & Delfs & 2005 & 92 & 122 & -0.3 & 24.8 \\
\hline New York & Walter & 1956 & 91 & 122 & $\mathbf{0 . 3}$ & 25.2 \\
\hline Vienna & Böhm & 1976 & 87 & 116 & 0.3 & 25.2 \\
\hline Stuttgart Radio & Schuricht & 1954 & 80 & 107 & 0.4 & 25.3 \\
\hline Royal Concertgebouw & Kondrashin & 1975 & 85 & 113 & 0.6 & 25.4 \\
\hline Brussels BRT & Rahbari & 1990 & 89 & 120 & 0.8 & 25.6 \\
\hline Houston & Eschenbach & 1993 & 90 & 121 & 1.1 & 25.8 \\
\hline Vienna & Bernstein & 1994 & 89 & 122 & 2.2 & 26.6 \\
\hline Amsterdam Concertgebouw & Mengelberg & 1940 & 93 & 127 & 2.4 & 26.8 \\
\hline New York & Rodzinski & 1950 & 94 & 128 & 2.9 & 27.1 \\
\hline Vienna & Kubelik & 1959 & 92 & 126 & 2.9 & 27.2 \\
\hline Berlin & Furtwängler & 1952 & 88 & 121 & 3.6 & 27.7 \\
\hline Boston & Haitink & 1991 & 83 & 114 & 3.8 & 27.8 \\
\hline Chicago & Solti & 1979 & 87 & 121 & 4.1 & 28.1 \\
\hline $\mathrm{NBC}$ & Toscanini & 1952 & 89 & 124 & 4.8 & 28.6 \\
\hline Berlin & Kempe & 1957 & 88 & 125 & 6.6 & 30.0 \\
\hline Royal Philharmonic & Beecham & 1959 & 83 & 118 & 6.8 & 30.1 \\
\hline New York & Bernstein & 1962 & 91 & 132 & 8.1 & 31.0 \\
\hline London Philharmonic & Weingartner & 1940 & 89 & 129 & 8.3 & 31.2 \\
\hline Bamberg & Swarovsky & 1970 & 81 & 119 & 9.5 & 32.1 \\
\hline Vienna & Furtwängler & 1945 & 86 & 128 & 10.6 & 33.0 \\
\hline Philadelphia & Stokowski & 1929 & 78 & 116 & 10.9 & 33.2 \\
\hline London Philharmonic & Beecham & 1946 & 84 & 128 & 12.2 & 34.2 \\
\hline New York & Damrosch & 1928 & 81 & 124 & 12.9 & 34.7 \\
\hline Berlin & Jochum & 1951 & 84 & 135 & 17.5 & 38.1 \\
\hline
\end{tabular}

$\begin{array}{lllll}\text { Mean } & 1974 & 91 & 119 & \mathbf{- 2 . 1} \\ \text { Median } & 1975 & 90 & 118 & \mathbf{- 2 . 9}\end{array}$




\section{NOTES}

$\dagger$ I am grateful to Justin London, Daphne Leong, and two anonymous reviewers for their comments on and criticisms of this research, and especially to Richard Cohn for his guidance and encouragement.

${ }^{1}$ See Hasty 1997 for a thorough discussion of the philosophical issues underlying this quality of meter.

${ }^{2}$ London acknowledges that this notion originates, in its modern psychological conception, with Gjerdingen 1989, who defined meter as "a mode of attending." One may also say that the concept of pitch class is "a mode of attending" more so than something in "the music itself," so perhaps meter is in familiar company.

${ }^{3}$ Sometimes the unit pulse is not articulated in the music, as in the "Von ewiger Liebe" analysis from Cohn 2001. This broadens the number of meters that could be potentially compared using this approach.

${ }^{4}$ Nonetheless, the fact that, of the three meters, only one is located in the center helps to make my “metric-tonicization” theory (Murphy 2007) non-trivial.

${ }^{5}$ Cohn speaks of the graph-theoretic distance relation providing "finer distinctions" $(2001,301)$ than those offered by dissimilar-pulse distance relations (as shown in his example 4c on p. 300). While this is true, the comparative applies to a small minority of instances in which a more complex ratio (like 9:4) holds between two pulse durations on the same level. For example, distance between the two peripheral meters of Figure $2 b(<1,2,4,12,36>$ and $<1,3,9,18,36>)$ is three in terms of dissimilarpulse distance but four in terms of graph-theoretic distance. In fact, one may erase the distinction by redesigning the dissimilar-pulse distance relation as a $3: 2$ distance relation, in which the distance between meters equals the minimum number of times the 3:2 ratio (or its reciprocal) is needed to 
convert the levels of one meter to the other. For example, in converting $<1,2,4,12,36>$ and $<1,3,9$, $18,36>$, four 3:2 ratios are required: one each for 2 to 3 and 12 to 18 , and two for 4 to 9 .

However, in his (as I count them) ten analytical observations regarding the Dvorak Scherzo (2001, 311-2), only one of them invokes the discrepancy between dissimilar-pulse distance and graphtheoretic distance: the upper strings move farther from the bass according to graph-theoretic distance but not according to dissimilar-pulse distance. Furthermore, this observation is unrelated to Cohn's primary finding: "whereas previously [the violins] stood in a symmetrical relationship to the cello around the central D state of the wind, now they stand in a symmetrical relationship with the more remote double bass, around the same central state." I suggest that, in most situations, dissimilar-pulse distance may ably serve as a rough approximate of graph-theoretic distance: only one of the fifteen (6 choose 2$)$ meter pairs in the Type II graph interpreting a span of 36 (Figure 2b) invokes this discrepancy, and only five of the forty-five (10 choose 2) pairs in the Type II graph interpreting a span of 72 (the one Cohn uses for the Dvorak Scherzo) invokes this discrepancy.

For the sake of completeness, I postulate that the dissimilar-pulse distance relation will always create a well-formed metric space (in the mathematical, not the musical, sense), after using a computer to confirm that the relation abides by the triangle inequality for Type II spaces interpreting spans of 36 and 72. The triangle inequality states that, for any vertices $\mathrm{A}, \mathrm{B}$, and $\mathrm{C}$, the sum of the distance between $\mathrm{A}$ and $\mathrm{B}$ and the distance between $\mathrm{B}$ and $\mathrm{C}$ should always be greater than or equal to the distance between $\mathrm{A}$ and $\mathrm{C}$.

${ }^{6}$ Pun intended. Using factor representation, [223], [232], and [322] are the three meters that interpret a span of 12. This trio is analogous to the three species of a perfect fourth from Medieval music theory, where " 3 " maps to a minor second, and "2" maps to a major second. Furthermore, the constituents of both (factors of 2 and 3 in a 12-span meter, and the tone and semitone in the perfect 
fourth) accrue multiplicatively to fill the span if one considers rational pitch intervals: for example, a 9/8 major second, a 256/243 minor second, and a 4/3 perfect fourth.

${ }^{7}$ These are also the four ars nova prolations of Johannes des Muris and Philippe de Vitry.

${ }^{8}$ Following Lewin and Cohn, this style of analyzing meters permits a secondary meter to earn a rank of "metrical state" that is just as high as that of the primary meter against which it is juxtaposed or superimposed, such that the two phenomena are in the same class despite any hierarchical relationship between them. This style is categorically different from (and intended as a complement to) the style of analyzing meters where a secondary meter becomes figure against the primary meter's ground, as in Krebs's (1999) study of metrical dissonance in Schumann's music. $\mathrm{Ng}(2006,67)$ nicely summarizes the relationship between these two styles in the context of Lewin's "transformational attitude."

${ }^{9}$ Douthett and Steinbach $(1998,253)$ discover that the six triads of any hexatonic system (defined in Cohn 1996), together with the two augmented triads whose union forms the hexatonic collection of the chosen system, form a cube under the adjacency relation of single semitonal displacement. These cubes are further explored in Cohn 1998 and Cohn 2000; the name "hexatonic cube," plus a discussion of its graph-theoretic dual, appears in Douthett 2008, 94-96.

${ }^{10}$ I thank Joti Rockwell for pointing this out to me, and stimulating this inquiry.

${ }^{11}$ These three terms come from London 2001b: “The beat level of the metric hierarchy serves as the temporal anchor for the other levels. Thus neither a 'top-down' approach (where one starts with the duration of an entire measure or larger unit and then proceeds to partition that span into beats, and those beats into subdivisions) nor a 'bottom-up' approach (where one starts with the shortest durations present on the musical surface, combines them into beats, and those beats into measures and so forth) is quite right. Rather, a sort of 'middle-out' perspective on metre seems most consonant with the way we attend to (as well as represent) rhythmic events." See London 2004, 44 (Figure 2.6) for examples of metric 
graphs or "trees" that are "middle-out." However, London is speaking of the primacy of the tactus as the common pulse when downplaying 'top-down' and 'bottom-up,' but a metric-cube analysis certainly does not have to locate the tactus on a middle layer, suggesting that one can maintain the primacy of the tactus and still (from a metric-cube perspective) examine the music from all three perspectives equally.

12 This is made more evident by a typical performance's tactus, which both changes from quarter-note to a dotted-quarter-note duration, and stands in between the two metric levels in question.

13 The difference between my dissimilar-factor distance relation and Cohn's dissimilar-pulse distance relation is somewhat analogous to the difference between John Roeder's (1987) and Clifton Callender's (2004) geometric configurations of ordered pitch class sets. As Callendar explains it, "The biggest difference between the two spaces...is that distance in T-class space [Callender's space] measures how far the voices move, whereas OI-space [Roeder's space] measures how much the intervals change." (12-13) In Roeder's space, the distance separating a diminished triad and an augmented triad is equivalent to the distance separating a major and minor triad, whereas the former distance is twice the latter in Callender's space. A couple sentences later, Callendar continues: "Depending on the analytical focus, either space may be more suitable than the other." (13) This statement applies just as well to Cohn's Type II metric spaces and my metric cubes.

${ }^{14}$ As reported by David Brodbeck $(1990,67)$, J.A. Fuller-Maitland $(1911,149)$ is an early Brahms scholar who makes this observation in print. Robert Bailey $(1990,405)$ also acknowledges the strong similarity. Raymond Knapp (2001, 140-45) goes one step further and recognizes that the Brahms allusion is not exactly equivalent to Wagner's: in Example 4 the A in the signaling harmony on the downbeats of mm. 32 and 34 would need to be a G\{sharp\}. Rather, he hears Brahms's chord as a hybrid of Wagner's "Sirens" chord and a similarly treated major-seventh chord in the first movement of 
Beethoven's Eroica. The slight difference between Wagner's and Brahms's music allows my analogy to attain greater clarity.

${ }^{15}$ Cohn (2000, 95-96), following personal communication from Jack Douthett, proposes this binary-code manner of representing the eight triads in a "hexatonic cube."

${ }^{16}$ While binary and ternary metric divisions/groupings are perhaps not opposites in the same manner as the opposites that Lewin's binary-code operations toggle between in his Babbitt analyses (presence of an attack vs. absence of an attack on a particular time point, or a performer's participation vs. being tacet in a particular movement), there is a long tradition of considering binary and ternary ratios as contraries: for example, Johannes de Muris uses the term "oppositum" when referring to binary's relationship to ternary $(1972,69)$, and Moritz Hauptmann $(1888,189-92)$ understands triple meter to be in opposition to duple meter, forming a thesis-antithesis pair in his dialectical system.

${ }^{17}$ This is a paraphrase of Lewin's Condition B to which GISs are subject $(1987,26)$.

${ }^{18} \mathrm{He}$ admits that the "interpeneteration and variation of material among the segments of the structure are really too extensive to permit even so general a schematic formation."

${ }^{19}$ Epstein's investigation of tempo proportions begins as one component of Epstein 1979 and is explored more thoroughly in Epstein 1995.

20 "Brahms has further prepared us to feel the second Presto move at the pulse of the preceding Tempo I by varying the motive of Tempo I to include a triplet....The triplet passage, begun in $\mathrm{m} .114$, extends 12 bars to the end of Tempo I. By virtue of the 1:1 relation in pulse, the triplets move at the same speed as the three notes in a bar of the 3/8 Presto. Thus the Presto tempo feels natural, for it continues the prior pulse.” (Epstein 1995, 536)

${ }^{21}$ These tempi were determined from markers placed in digital audio files created by tapping the quarter-note pulse of $\mathrm{mm}$. 1-8, and the notated dotted quarter pulse for mm. 126-144. The application 
Peak rounds the markers to the nearest thousandth of a second. The timespans between adjacent markers are calculated, and the average of only those timespans that do not exceed one standard deviation of the set of differences is then used to calculate the tempo. This keeps occasional tempo fluctuations, both in the recordings and in my unavoidably less-than-perfect tapping, from significantly altering the overall tempo. For example, Harnoncourt, in his 1997 recording with the Berlin Philharmonic, considerably stretches out the third beats of mm. 4 and 6 to $15 \%$ and $20 \%$, respectively, of the average duration of the other beats in the first half; these timespans were discarded by the standard-deviation method. (However, such deviant timespans still may affect the overall tempo, as all timespans are used to calculate the standard deviation.)

${ }^{22}$ According to Steve Haflich and Lora Gingerich Dobos, Epstein conducted Brahms's Second Symphony with the MIT Symphony Orchestra at least in 1973, if not also as part of other concert seasons. However, despite the generous efforts of MIT's current music librarian, Peter Munstedt, and Epstein's daughter Eve, no recording has been located to determine whether or not Epstein put his proposed tempo proportion into his own performance practice.

${ }^{23}$ Views from non-conductors support this view as well. Although Kalbeck called the C Presto a “prickelnder Geschwinder-Walzer" (Kalbeck 1910, 171; translated as "pungent quick-waltz” by Peter Palmer in Brinkmann 1995, 160), others tend to view the C Presto as a scherzo, such as Brinkmann: "The second quick dance comes around in m. 156 to the character of the scherzo." $(1995,162)$ Following Brinkmann, who compares the characters of the third movements of Brahms's and Beethoven's third symphonies, Knapp $(2001,182)$ likens the short-long rhythms of mm. $144-147$ in the Brahms movement to those of mm. 373ff in the Beethoven movement. If one adopts Beethoven's metronome marking for his scherzo, the tempo for Brahms's Allegretto would have to run at a blistering pace of $\downarrow=116$ to incorporate both Epstein's proportion and this intertextual allusion. 
${ }^{24}$ If the Allegretto and C Presto tempi are chosen solely based on the optimal suitability of each section's expressive character (assuming that the average of the collective wisdom of the sixty-seven surveyed conductors determines this optimization), then these two variables should be independent of one another. However, there is a modest correlation between these two tempi among the sixty-seven surveyed recordings; the Pearson product-moment correlation coefficient (r) is .26, and it increases to .36 with the elimination of three (less than $5 \%$ of the total) outliers.

${ }^{25}$ A few recordings interpret the grace note as shorter than a sixteenth note. For example, Stokowski's 1929 recording with the Philadelphia Orchestra consistently interprets the grace notes closer to one-sixth, rather than to one-fourth, of the duration of the Allegretto quarter note.

${ }^{26}$ For London, the presence or absence of regular sixteenth-note divisions of the quarter-note tactus in the A sections amounts to two different kinds of meter. The fact that the sixteenths do not pervade the A section would lead London to say that the meter is different from a hypothetical A section in which a sixteenth-note pulse was continuously heard. To reconcile London's finer definition of meter with the broader brush strokes used in Figure 9 et al., my meter of a section may be considered as the union - the "maximum representative meter" - of all of the pulses in the "London meters" in the section. However, each of the A sections also features intermittent eighth-note triplets that my choice of common pulse inherently cannot account for: small but nonetheless significant collateral damage resulting from a focus on those performances that opt for the 3:4 proportion. If a maximum representative meter is to be a fully consonant meter, then its creation may have to be regulated according to its broader analytical utility, such as possessing the common pulse. For example, a metric-cube analysis using Epstein's proportion would instead welcome the eighth-triplet pulse and reject the sixteenth-note pulse in the maximum representative meter of the A section. The submetrical dissonance between these two mutually exclusive pulses, indirect in the A section but direct in the A' music preceding the C Presto 
(see Example 5f), may be fancifully heard as a compositional analogue to the conflict between Epstein's and the "average" conductor's C Presto eighth-note durations, and to the conflict between the two possible maximum representative meters of the A sections.

${ }^{27}$ London 2002 argues that pitch-class space and metric space are inherently non-isomorphic because the former, at least in the form of the equal-tempered toroidal Tonnetz, is non-planar while the latter, at least in the form of metric pulse durations connected by factors of twos and threes, is planar. While metric 2-cubes and 3-cubes are planar (as evidenced by Figures 3 and 4a), all metric n-cubes where $n \geq 4$ are non-planar.

${ }^{28}$ If one uses the average tempo of the interpretations documented in the Appendix (Allegretto's $\downarrow=91)$, then all of the pulses in all of the meters analyzed in Figure 9 fit within a "temporal envelope" ranging from 100 milliseconds to 6 seconds, which, according to London 2004, defines the upper and lower limits of meter. This also holds true for the previous analysis of op. 90 , i, as well as the upcoming analysis of op. 51/2, iii and iv, assuming typical tempos $(0 . \approx 60$ for the former and the same for the finale of the latter).

${ }^{29}$ A variation on metric-cube analysis uses not a fixed common pulse as a point of reference for each meter in the cube, but rather the work's tactus or other contextually-defined time span, even though its duration may increase or decrease over the course of the work. If the tactus is used as the point of reference in constructing an analysis of this movement akin to Figure 9, then a couple benefits immediately become available: one could account for the changes between duple and triple subdivisions of the tactus in the A sections (particularly A'), and one would not need to fret over whether or not the sixteenth note is indeed a unifying pulse for the movement. Related to this second point, a 3-cube with the tactus as the second fastest pulse rather than a 4-cube would more efficiently represent the metric variety in the movement. However, one would need to choose between tactus durations of a one- or a 
two-measure span for the C Presto. (It is presumed that the tactus remains unchanged entering the B Presto.) A two-measure tactus for the C Presto results in the same exact analysis as Figure 9. Therefore, the "stepwise" operation $<0001>$ connecting $\mathrm{A}$ ' and $\mathrm{C}$ well captures the interpretation that "the only difference between the two meters is the submetrical level below the duple division of the beat," despite the change of tactus from A' to C. However, if a one-measure tactus is used for C, then the "stepwise" operation that occurs at five other metric transitions no longer holds from $\mathrm{A}^{\prime}$ to $\mathrm{C}$. Yet the fact that a significant stretch of music in the C Presto (mm. 144-180) can be heard as a compression of material from the B Presto (mm. 51-87) supports this interpretation. Furthermore, a "stepwise" narrative reengages in the transition to A": stepping over the "false retransition" of mm. 180-87, a $<010>$ operation transforms the [223] of mm. 156-79 into the [233] of mm. 188-189, then a $<001>$ transforms this [233] meter into the [232] of mm. 190-191 and A'. I am indebted to an anonymous reader for making this suggestion.

${ }^{30}$ Epstein 1995, 537: "By virtue of the 1:1 relation in pulse, the triplets move at the same speed as the three notes in a bar of the $3 / 8$ presto. Thus the Presto tempo feels natural, for it continues the prior pulse." (536) “Tempo I [the A' section] cadences via a ritard; the return to the prevalent beat at the Presto effects a return to a prior state. The readiness potential for this return is cued not only by the prior pulse itself, but also by the triplet feeling that closes Tempo I, since the triplets are congruent with a bar of Presto II. The transition thus feels comfortable, psychologically and physiologically comfortable, a feeling abetted by biochemical effectors such as endorphins and other neurotransmitters that are intrinsic to this process."

31 "In the second Presto, the shift [in tempo] is even more dramatic, since the first statement of the main theme is omitted, and since the remainder is prefaced by twelve bars of the secondary theme in the wrong key." (Knapp 1997, 155) 
32 “The striking F-sharp major in the strings, with the pizzicato bass, in the third movement's closing section is plainly analogous to the opening movement's second theme in F-sharp major (mm. 74ff.), whose elegiac dance character recalls Brahms's Liebeslieder-Walzer, and which also is played over a pizzicato bass.” (Brinkmann 1995, 169)

${ }^{33}$ In addition to Lewin 1981 and Cohn 2001, recent analytical studies of selected works by Brahms, such as Smith 2001, McClelland 2004 and 2005, and Smith 2006, have recognized synchronicities and concerted interaction between consonant or tonic pitch states and consonant or primary metrical phenomena, and between dissonant or non-tonic pitch states and dissonant or secondary metrical phenomena.

${ }^{34}$ This is the correspondence between "logical tonic" and "rhetorical tonic" meters that I have found in many works of Brahms and other nineteenth-century composers (Murphy 2007).

${ }^{35}$ The orientation of the analogy between triple-count frequency and pitch frequency is inverted from that which is used in Cohn 2001 and Murphy 2007, but matches the analogical mapping used in Lewin 1981.

${ }^{36}$ The single hemiola between the Allegretto's [2322] and the [3222] in mm. 51-62 of the B Presto is not heard in direct succession; the pure duple [2222] that opens the B Presto in m. 33 splits their metric-cube distance of two and makes the metric-cube progression stepwise (and arguably even smoother than without it). In this context, [2222] is analogous to a "coupling chord," defined by Douthett and Steinbach $(1998,253)$ as a symmetrical sonority, such as an augmented triad or diminished seventh chord, that connects via a "smallest-step relation" two other chords in the same equivalence class that do not form the "smallest-step" relation on their own. Indeed, mm. 49-50 include a Gaug triad that allows the immediately preceding G-major triad to pass to the C-major triad of $\mathrm{m}$. 51 with entirely semitonal motion in its upper voice leading; this is the only augmented triad in the entire movement. 
${ }^{37}$ One of the most immediate ways to experience the degree of "large-scale dissonance" (to borrow a phrase that Charles Rosen $(1988,229)$ uses to characterize subordinate-theme modulations) of the C Presto's tempo in relation to the Allegretto's tempo is to employ an extreme form of Andrew Imbrie's “conservative" hearing, which pushes an entrainment to a particular metrical framework "as far forward as possible to see how long one could cling to an established pattern." (Imbrie 1973, 65) To do so, continue to beat the Allegretto tactus and 3/4 meter as the C Presto begins during one of the many performances (see Appendix) in which C's tactus frequency is 4/3 that of A's. Two forms of disparity arise: the double-hemiola incongruity, and the strong urge to short circuit and restart the Allegretto periodicities every six Presto measures, since [2322] and [2323] have different hypermetric durations. I believe such conscious sensations of conflict are akin to the experience of A major as a "wrong" key.

${ }^{38}$ Semitonal transpositions in particular of the refrain late in a rondo or sonata-rondo movement can be found, for example, in the second movement of Mozart's Sonata for Keyboard and Violin in E\{flat\} Major, K. 481 (A fflat\} major $\rightarrow$ A major), and in the finales to Beethoven's Piano Sonata op. 7 (E\{flat $\}$ major $\rightarrow$ E major) and First Piano Concerto (C major $\rightarrow$ B major).

${ }^{39}$ This is, in some sense, the paradox Lewin 1984 uncovers in Parsifal concerning the pitch D and its chromatic variants.

${ }^{40}$ Bass 1988 discusses semitonal substitutions or "shadows" of diatonic key areas in music of Prokofiev and Shostakovich, and McCreless 1996, inter alia, responds to Bass's ideas.

${ }^{41}$ In most of these cases, both the metrical hierarchy and the placement of the strong beats of the hierarchy are transparent. However, while mm. 91-96 clearly project a [222] pure duple meter, there are multiple plausible downbeats of the whole-note pulse, the slowest pulse in this meter. David Clampitt, in personal communication, has argued for the placement of the second beat of m. 91 on a 2/4 downbeat 
for multiple reasons, including the fact that the high A makes more sense as part of a 4-3 suspension, and the change of meter on the downbeat of m. 98 is also a 2/4 downbeat with this approach.

${ }^{42}$ In op. 38, the E-major tonic that ends the penultimate movement functions as dominant of the supertonic A-minor triad that opens the G-major finale. In op. 51/1, the finale's opening motive begins as if in F minor, the key and mode of the previous movement, but then this music is quickly repositioned as subdominant in the finale's key of $\mathrm{C}$ minor. In op. 68 , the penultimate movement concludes in $\mathrm{A}\{$ flat $\}$ major, and the finale begins with bass pitches $\mathrm{C}, \mathrm{B}\{$ flat $\}$, and $\mathrm{A}\{$ flat $\}$, which transform into the opening of a descending lament tetrachord in the finale's key of $\mathrm{C}$ minor. In op. 88 , the penultimate movement concludes in A major, and the F-major finale begins with a tonic triad in first inversion; the common bass note of A serves as the link. In op. 90, the penultimate movement is in $\mathrm{C}$ minor, and the finale starts with the pitches $\mathrm{C}, \mathrm{B}$, and $\mathrm{C}$, which are soon subsumed within the finale's tonality of $\mathrm{F}$ minor. In op. 108, the penultimate movement ends on an $\mathrm{F}\{$ sharp $\}$-minor tonic, and the finale begins on the dominant of $\mathrm{D}$ minor; the distant tonal relationship between the movements is facilitated by the two common tones of $\mathrm{A}$ and $\mathrm{C}$ \{sharp\}. This technique is not restricted to the final two movements: for example, in the four-movement op. 34, the second movement concludes in A fflat\} major, then the Fminor third movement begins with bass Cs and an arpeggiation through an A\{flat\}-major triad.

${ }^{43}$ Among thirty-seven of Brahms's multi-movement instrumental works (opp. 1, 2, 5, 8, 15, 16, $18,25,26,34,38,40,51 / 1,51 / 2,60,67,68,73,77,78,83,87,88,90,98,99,100,101,102,108,11$, $111,114,115,120 / 1,120 / 2)$, there are 107 pairs of successive movements, and only twelve of these pairs $(11 \%)$ employ the same key and mode to end the first movement of the pair and begin the second movement of the pair. 
${ }^{44}$ The analysis and its notation in Figure 13 adopts, as well as an analysis of a work from no earlier than the 1860s can, the Sonata Theory of Hepokoski and Darcy 2006. Following Whittall's (1987) interpretation of "three cadential closes," I propose the first of them in $\mathrm{m} .71$ as the EEC.

${ }^{45}$ This dualistic relationship between tonality and meter also adds yet another common feature between the first movement of Beethoven's op. 132 and the finale of Brahms's op. 51/2. Both are in the key of A minor, and both can be interpreted to have three expositions. In both cases, each of the three expositions begin with $\mathrm{P}$ material; however, Brahms's statements are all in A minor, whereas Beethoven's second exposition begins with a transposition of $\mathrm{P}$ material to $\mathrm{E}$ minor. In both cases, the first two of the three expositions present the first $\mathrm{S}$ theme in $\mathrm{C}$ major and $\mathrm{F}$ major (the order is reversed in the Brahms from the Beethoven), and the third exposition presents the first $\mathrm{S}$ theme in A major. Both Beethoven and Brahms assign a quick-moving, hocket-like accompaniment to the same pair of instruments for the first two presentations of the first $\mathrm{S}$ theme: second violin and viola for the C-major theme, and viola and 'cello for the F-major theme. More relevant to the key-meter analogy I propose in the Brahms movement is the fact that the $\mathrm{S}$ theme is always presented in a $4+4$ antecedent-consequent grouping, whereas the $\mathrm{P}$ theme uses a sentence structure early in the movement and only assumes more of a periodic structure toward the end of the movement. Therefore, while the first $\mathrm{S}$ theme finally arrives at the key best associated with the $\mathrm{P}$ theme only after exploring other tonal options, the $\mathrm{P}$ theme finally arrives at a periodic structure best associated with the first $S$ theme only after exploring other options of form and grouping. In Beethoven's movement, the significance of the symmetry of $\mathrm{F}$ and $\mathrm{C}$ around $\mathrm{A}$, as well as the P theme's formal transformations, are explored in detail by Robert Morgan (2003, 35 and 38). 
a. $<1,2,4,12>$

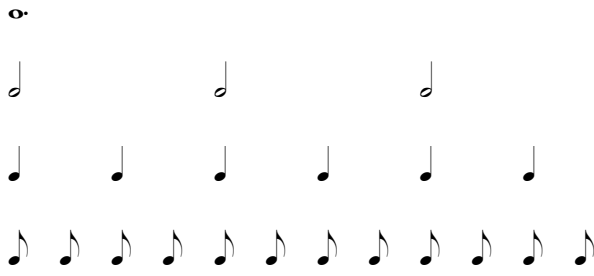

b. $<1,6,12>$

o.

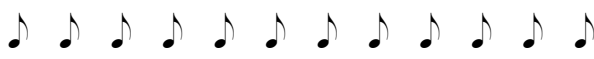

c. $<1,4,6,12>$

o.

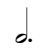

○

$\therefore D D D D D D$
Fully

Consonant Consonant

Yes

Yes

Yes

No

No

No

\section{Example 1}

Three metrical interpretations of a dotted whole-note $\operatorname{span}(\mathrm{L}=\mathbf{o} \cdot=12, \bullet=1)$ 
Murphy, Scott. "Metric Cubes in Some Music of Brahms," Journal of Music Theory 53/1 (Spring, 2009): 1-56.

Publisher's official version http://dx.doi.org/10.1215/00222909-2009-020. Open Access version: http://hdl.handle.net/1808/9937.

\begin{tabular}{|c|c|c|}
\hline $\begin{array}{c}\text { Pure } \\
\text { duple } \\
\text { meters }\end{array}$ & $\begin{array}{c}\text { Mixed } \\
\text { meters }\end{array}$ & $\begin{array}{c}\text { Pure } \\
\text { triple } \\
\text { meters }\end{array}$ \\
\cline { 3 - 3 } & &
\end{tabular}

Figure 1

Cohn's Type I metric space 
Murphy, Scott. "Metric Cubes in Some Music of Brahms," Journal of Music Theory 53/1 (Spring, 2009): 1-56.

Publisher's official version http://dx.doi.org/10.1215/00222909-2009-020. Open Access version: http://hdl.handle.net/1808/9937.

\begin{tabular}{|c|c|c|}
\hline $\begin{array}{c}c 1,2,4,12> \\
{[322]}\end{array}$ & $\begin{array}{c}<1,2,6,12> \\
{[232]}\end{array}$ & $<1,3,6,12>$ \\
\cline { 3 - 3 } & & $223]$ \\
& & \\
\end{tabular}

Figure $2 \mathrm{a}$

One example of Cohn's Type II metric space 
Murphy, Scott. "Metric Cubes in Some Music of Brahms," Journal of Music Theory 53/1 (Spring, 2009): 1-56.

Publisher's official version http://dx.doi.org/10.1215/00222909-2009-020. Open Access version: http://hdl.handle.net/1808/9937.

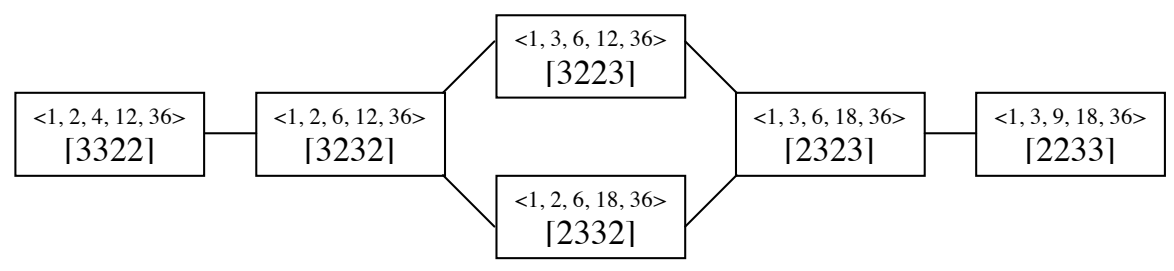

Figure $2 b$

Another example of Cohn's Type II metric space 


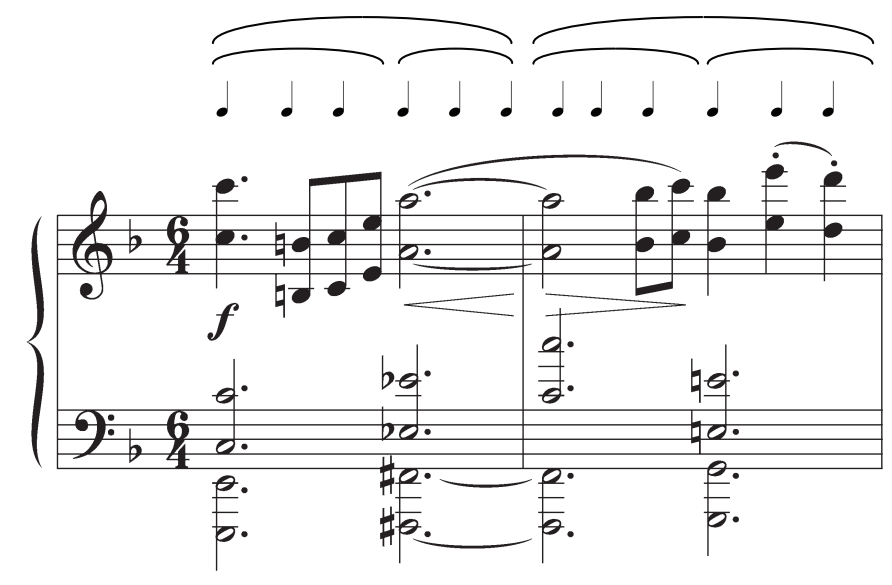

Example 2

Four meters in Brahms, Third Symphony, first movement

Example 2a

Primary theme's primary meter (PtPm): 6/4, <1/4, 3/4, 1 1/2>, [23] (mm. 7-8 given as one example) 
Murphy, Scott. "Metric Cubes in Some Music of Brahms," Journal of Music Theory 53/1 (Spring, 2009): 1-56.

Publisher's official version http://dx.doi.org/10.1215/00222909-2009-020. Open Access version: http://hdl.handle.net/1808/9937.

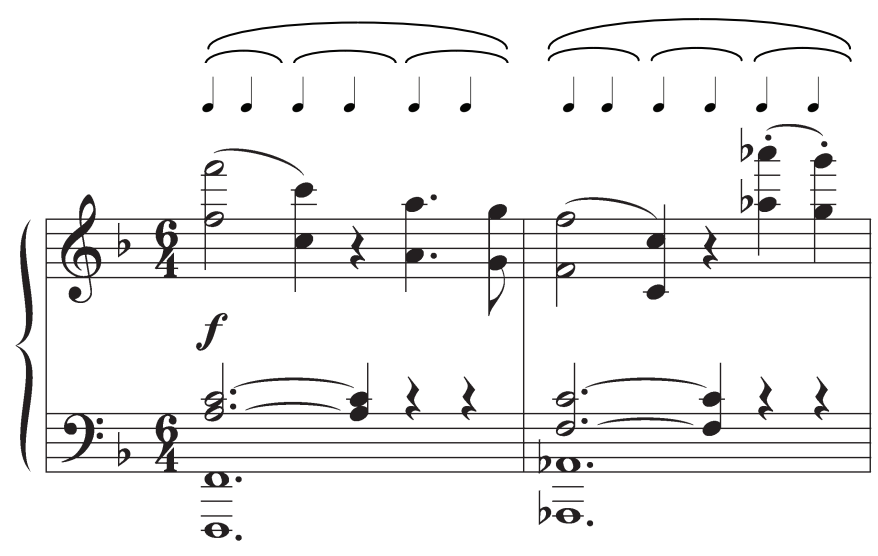

Example $2 b$

Primary theme's secondary meter (PtSm): 3/2, <1/4, 1/2, 1 1/2>, [32] (mm. 3-4 given as one example) 
Murphy, Scott. "Metric Cubes in Some Music of Brahms," Journal of Music Theory 53/1 (Spring, 2009): 1-56.

Publisher's official version http://dx.doi.org/10.1215/00222909-2009-020. Open Access version: http://hdl.handle.net/1808/9937.

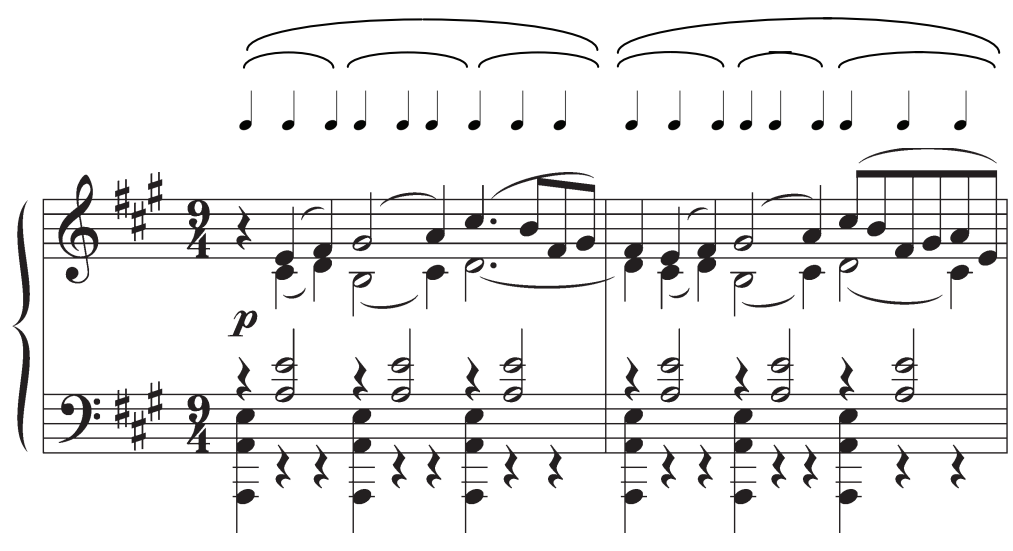

Example 2c

Secondary theme's primary meter (StPm): 9/4, $<1 / 4,3 / 4,9 / 4>$, [33] (mm. 36-37 as one example) 
Murphy, Scott. "Metric Cubes in Some Music of Brahms," Journal of Music Theory 53/1 (Spring, 2009): 1-56.

Publisher's official version http://dx.doi.org/10.1215/00222909-2009-020. Open Access version: http://hdl.handle.net/1808/9937.

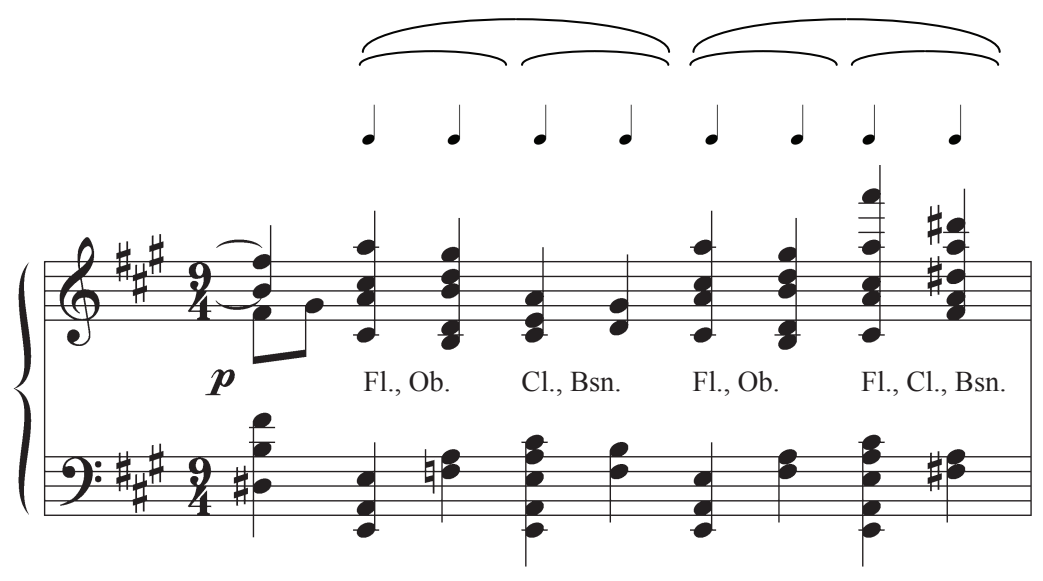

Example 2d

Secondary theme's secondary meter (StSm): 4/4, <1/4, 2/4, 1>, [22] (m. 46 as one example) 
Murphy, Scott. "Metric Cubes in Some Music of Brahms," Journal of Music Theory 53/1 (Spring, 2009): 1-56.

Publisher's official version http://dx.doi.org/10.1215/00222909-2009-020. Open Access version: http://hdl.handle.net/1808/9937.

$\stackrel{\substack{22] \\ \mid}}{[32]-[33]}$

Figure 3

A 2-cube 
Murphy, Scott. "Metric Cubes in Some Music of Brahms," Journal of Music Theory 53/1 (Spring, 2009): 1-56.

Publisher's official version http://dx.doi.org/10.1215/00222909-2009-020. Open Access version: http://hdl.handle.net/1808/9937.

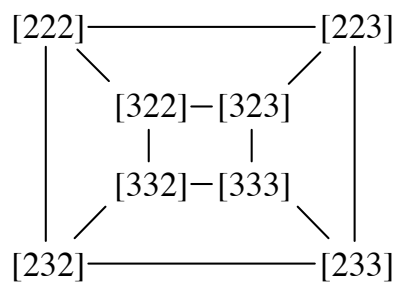

Figure 4a

A planar 3-cube 
Murphy, Scott. "Metric Cubes in Some Music of Brahms," Journal of Music Theory 53/1 (Spring, 2009): 1-56.

Publisher's official version http://dx.doi.org/10.1215/00222909-2009-020. Open Access version: http://hdl.handle.net/1808/9937.

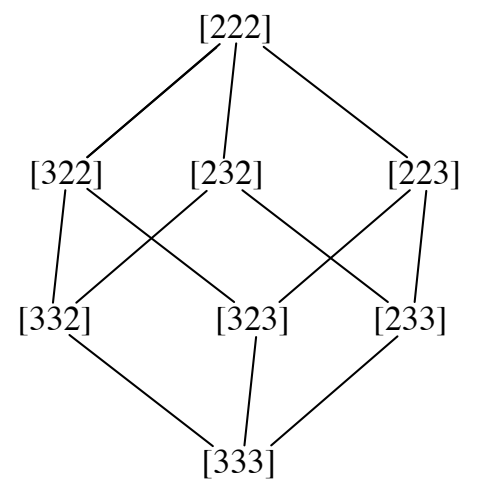

Figure $4 b$

A non-planar 3-cube 
Murphy, Scott. "Metric Cubes in Some Music of Brahms," Journal of Music Theory 53/1 (Spring, 2009): 1-56.

Publisher's official version http://dx.doi.org/10.1215/00222909-2009-020. Open Access version: http://hdl.handle.net/1808/9937.

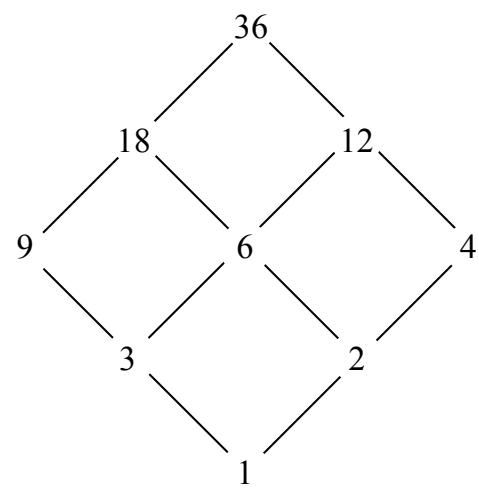

Figure 5

Ski-hill graph that corresponds to Figure $2 b$ 
Murphy, Scott. "Metric Cubes in Some Music of Brahms," Journal of Music Theory 53/1 (Spring, 2009): 1-56.

Publisher's official version http://dx.doi.org/10.1215/00222909-2009-020. Open Access version: http://hdl.handle.net/1808/9937.

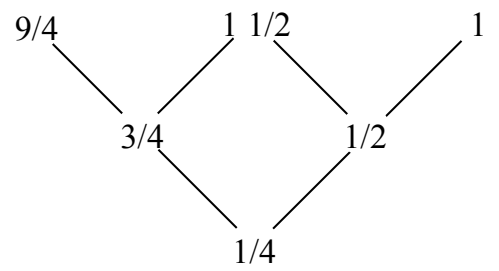

Figure 6a

The "bottom-up" graph of pulses that corresponds to Figure 3 and uses the common pulse and pulse nomenclature of Example 2 
Murphy, Scott. "Metric Cubes in Some Music of Brahms," Journal of Music Theory 53/1 (Spring, 2009): 1-56.

Publisher's official version http://dx.doi.org/10.1215/00222909-2009-020. Open Access version: http://hdl.handle.net/1808/9937.

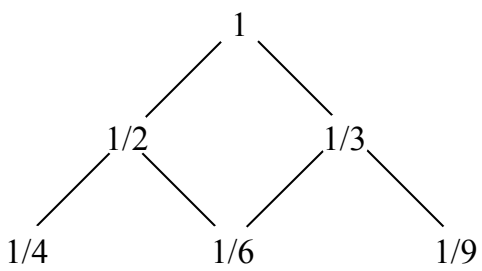

\section{Figure 6b}

A "top-down" graph of pulses that corresponds to Figure 3 
Murphy, Scott. "Metric Cubes in Some Music of Brahms," Journal of Music Theory 53/1 (Spring, 2009): 1-56.

Publisher's official version http://dx.doi.org/10.1215/00222909-2009-020. Open Access version: http://hdl.handle.net/1808/9937.

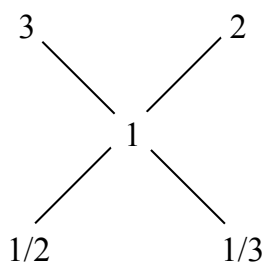

Figure 6c

A "middle-out" graph of pulses that corresponds to Figure 3 


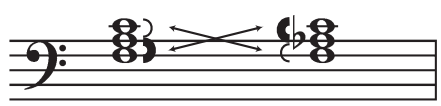

\section{Example 3}

Comparison of two harmonic relations and their intervallic transformations. (Thin brackets indicate minor thirds, thick brackets indicate major thirds.)

\section{Example 3a}

Intervals remain unchanged, swap positions 
Murphy, Scott. "Metric Cubes in Some Music of Brahms," Journal of Music Theory 53/1 (Spring, 2009): 1-56.

Publisher's official version http://dx.doi.org/10.1215/00222909-2009-020. Open Access version: http://hdl.handle.net/1808/9937.

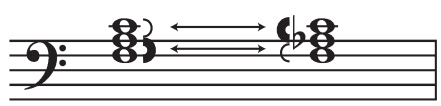

Example 3b

Intervals toggle, remain in same positions 
Murphy, Scott. "Metric Cubes in Some Music of Brahms," Journal of Music Theory 53/1 (Spring, 2009): 1-56.

Publisher's official version http://dx.doi.org/10.1215/00222909-2009-020. Open Access version: http://hdl.handle.net/1808/9937.

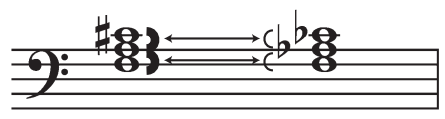

\section{Example 3c}

Intervals toggle, remain in same positions 
Murphy, Scott. "Metric Cubes in Some Music of Brahms," Journal of Music Theory 53/1 (Spring, 2009): 1-56.

Publisher's official version http://dx.doi.org/10.1215/00222909-2009-020. Open Access version: http://hdl.handle.net/1808/9937.

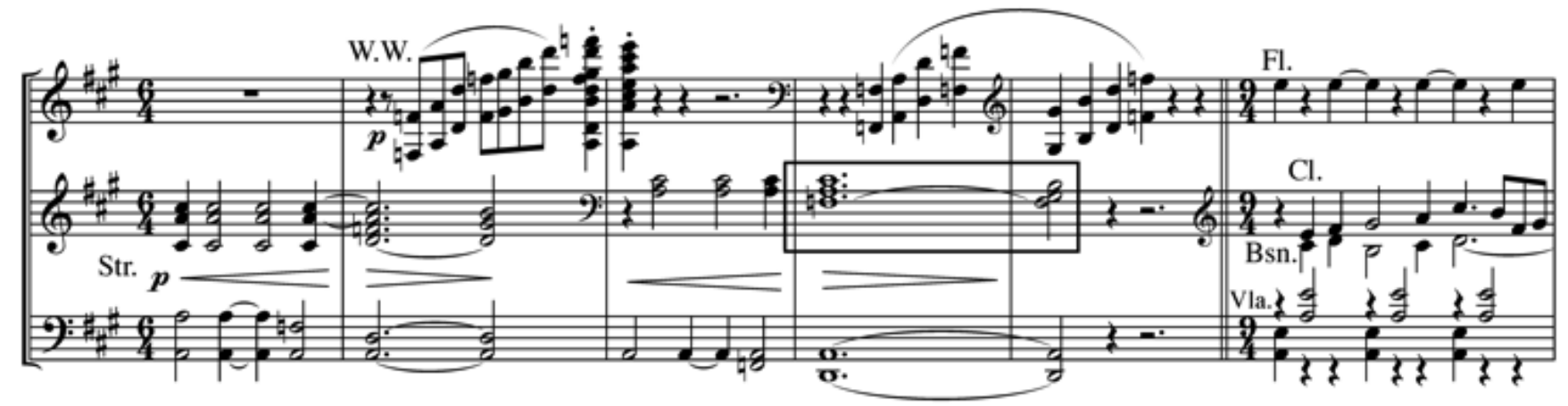

Example 4

Brahms, Third Symphony, first movement, mm. 31-36 
Murphy, Scott. "Metric Cubes in Some Music of Brahms," Journal of Music Theory 53/1 (Spring, 2009): 1-56.

Publisher's official version http://dx.doi.org/10.1215/00222909-2009-020. Open Access version: http://hdl.handle.net/1808/9937.

[23]

PtPm (Ex. 2a)

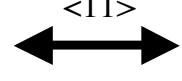

[32]

[33]

$\underbrace{[22]}_{\text {StSm (Ex. 2d) }}$

StPm (Ex. 2c)

Figure 7

Isographic networks of meters from the first movement of Brahms's Third Symphony 
Murphy, Scott. "Metric Cubes in Some Music of Brahms," Journal of Music Theory 53/1 (Spring, 2009): 1-56.

Publisher's official version http://dx.doi.org/10.1215/00222909-2009-020. Open Access version: http://hdl.handle.net/1808/9937.

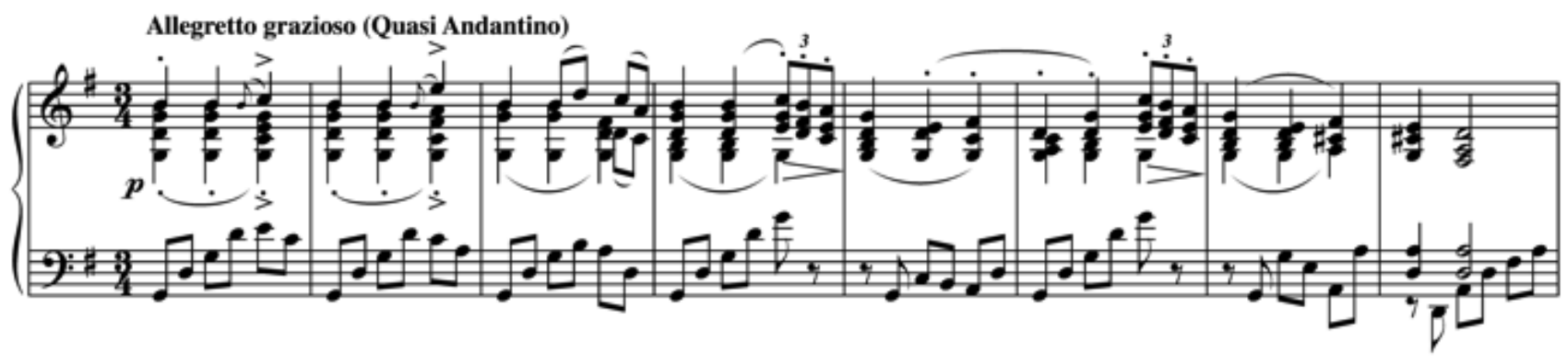

Example 5

Brahms, Second Symphony, third movement, excerpts

Example 5a

Measures 1-8 (opening of A)

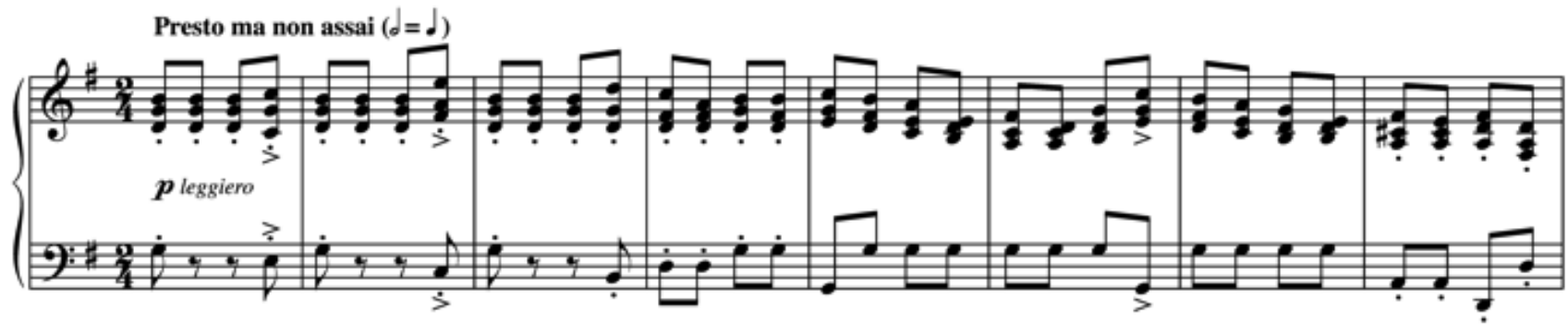

Example 5b

Measures 33-40 (opening of B)

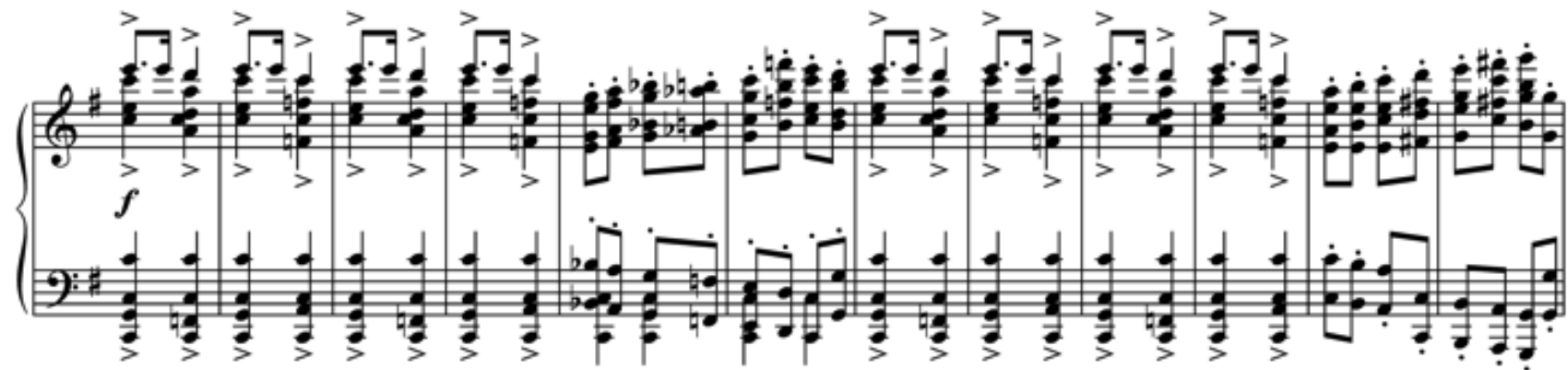

Example 5c

Measures 51-62 (continuation of B)

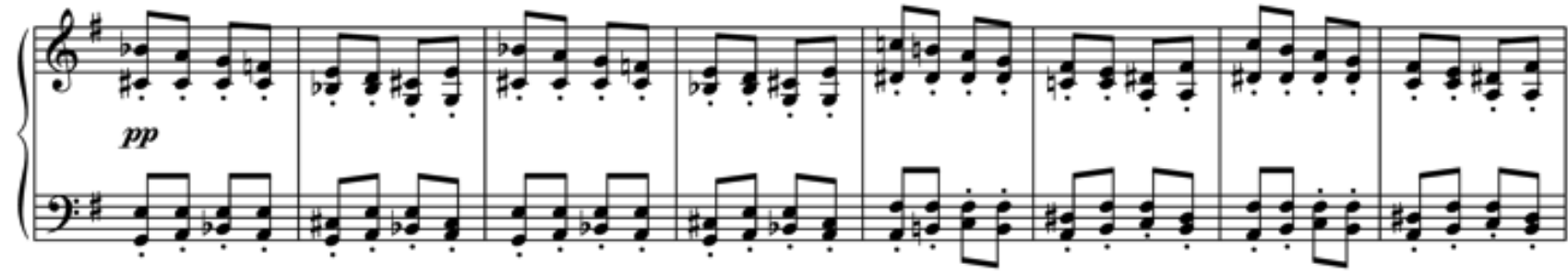

Example 5d

Measures 63-70 (continuation of B) 
Murphy, Scott. "Metric Cubes in Some Music of Brahms," Journal of Music Theory 53/1 (Spring, 2009): 1-56.

Publisher's official version http://dx.doi.org/10.1215/00222909-2009-020. Open Access version: http://hdl.handle.net/1808/9937.

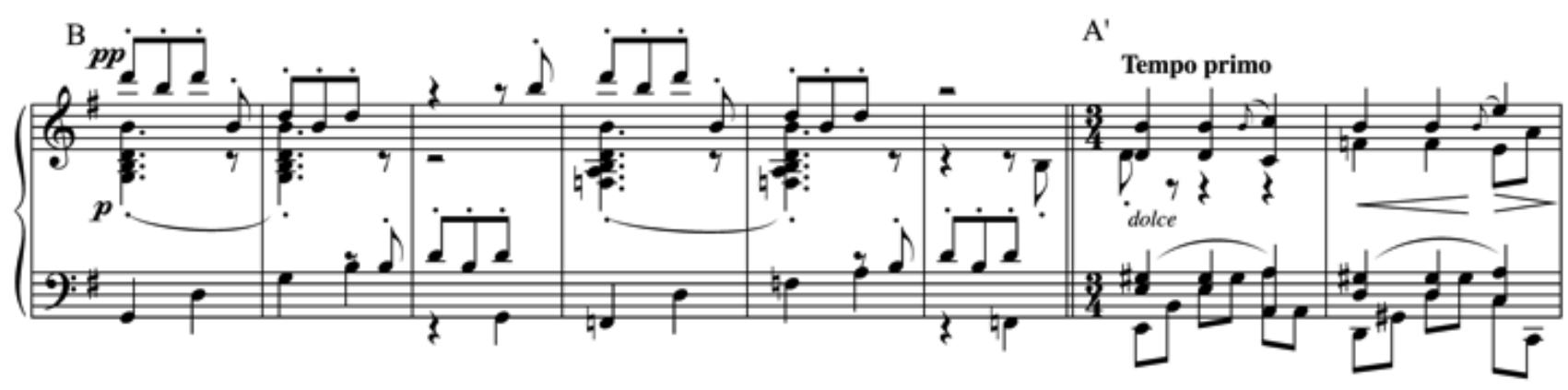

Example 5e

Measures 101-6 (retransition from B to A')

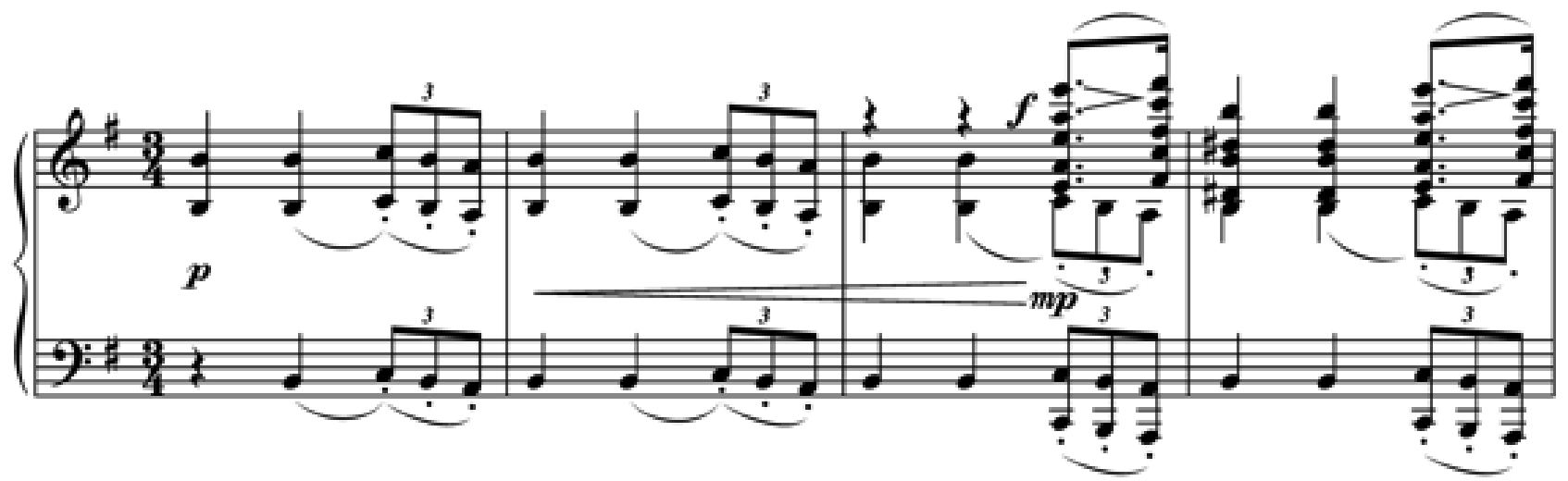

Example 5f

Measures 114-117 (part of A’)

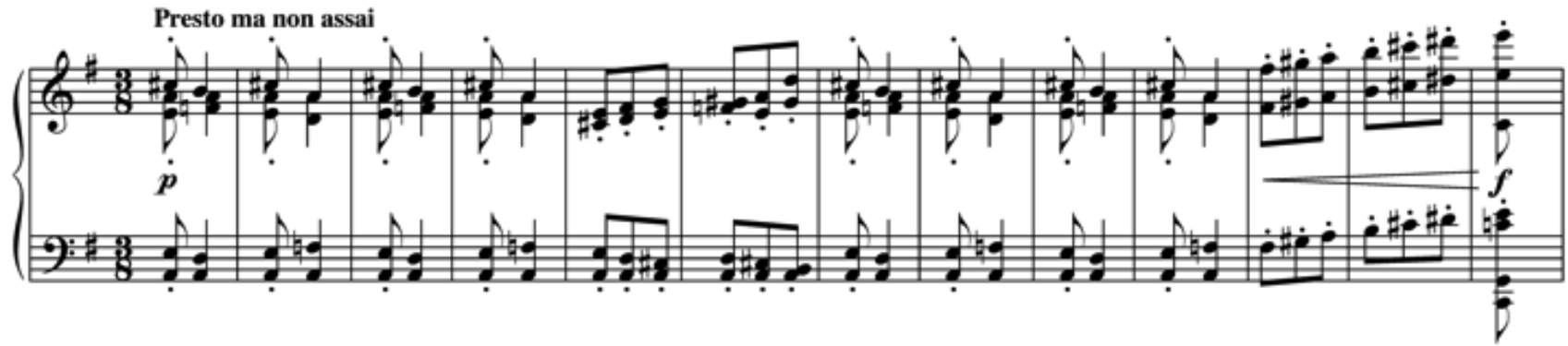

Example 5g

Measures 132-144 (beginning of C)

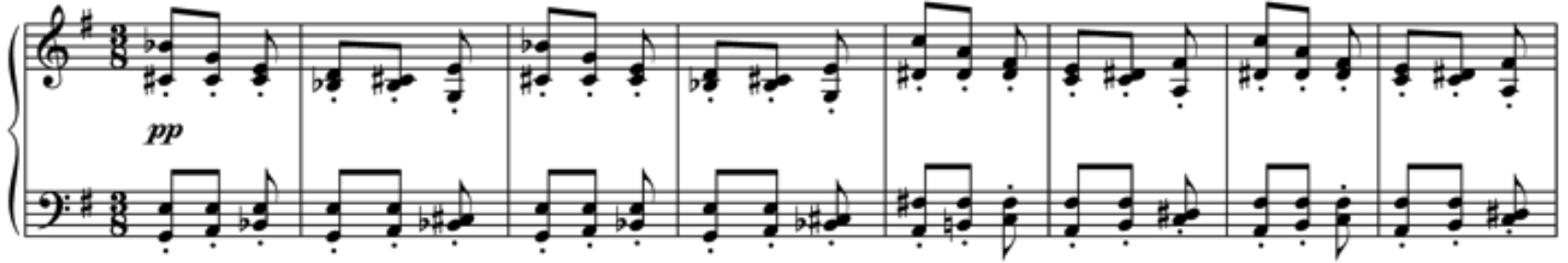

Example 5h

Measures 156-163 (continuation of C) 


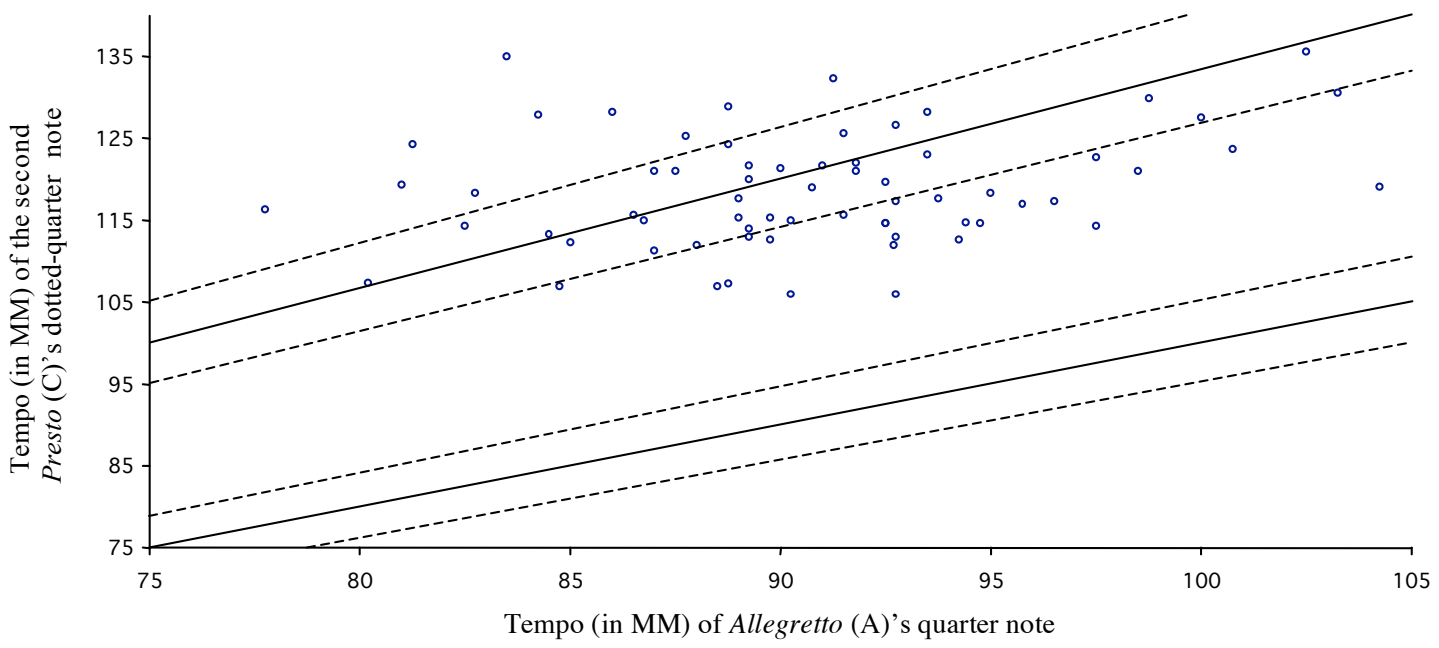

Figure 8

Chart of tempi in sixty-seven interpretations of Brahms, Second Symphony, third movement 
Murphy, Scott. "Metric Cubes in Some Music of Brahms," Journal of Music Theory 53/1 (Spring, 2009): 1-56.

Publisher's official version http://dx.doi.org/10.1215/00222909-2009-020. Open Access version: http://hdl.handle.net/1808/9937.

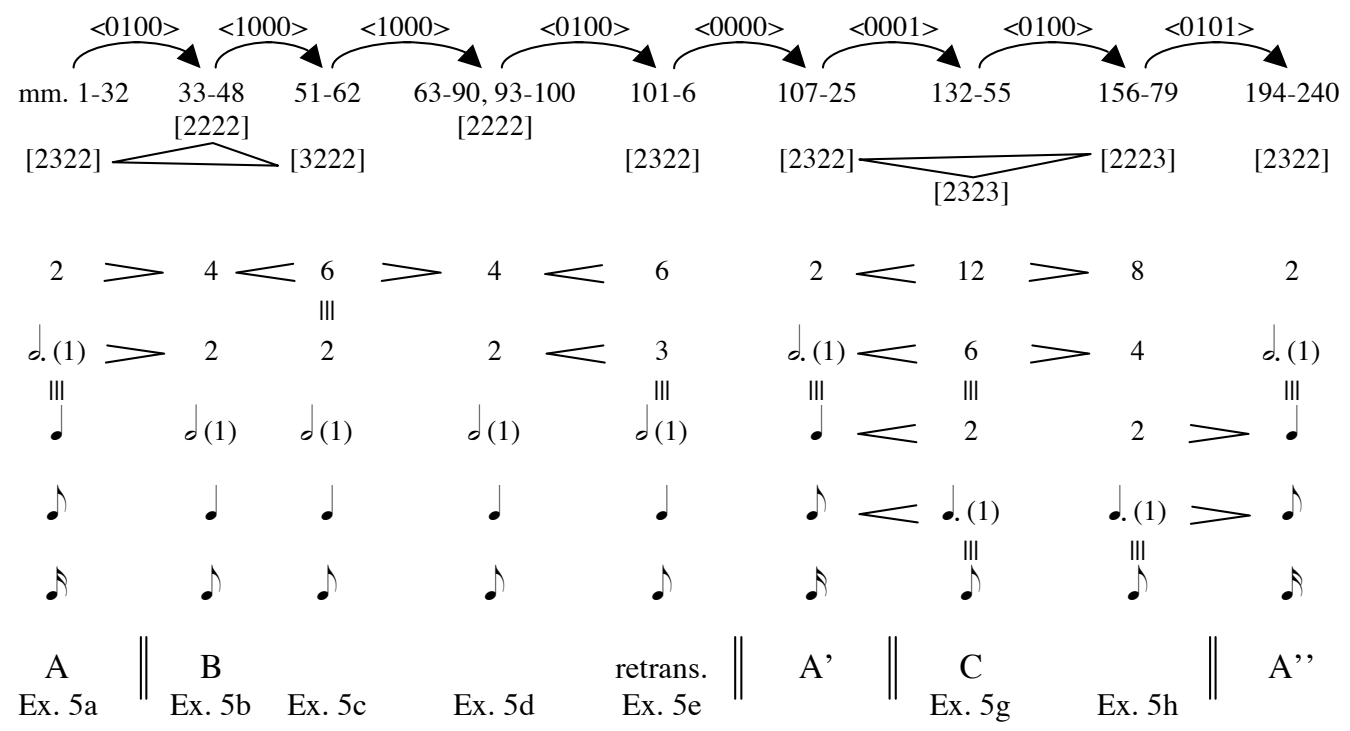

Figure 9

Analysis of 4-cube meters and intervening operations in Brahms, Second Symphony, third movement 
Murphy, Scott. "Metric Cubes in Some Music of Brahms," Journal of Music Theory 53/1 (Spring, 2009): 1-56.

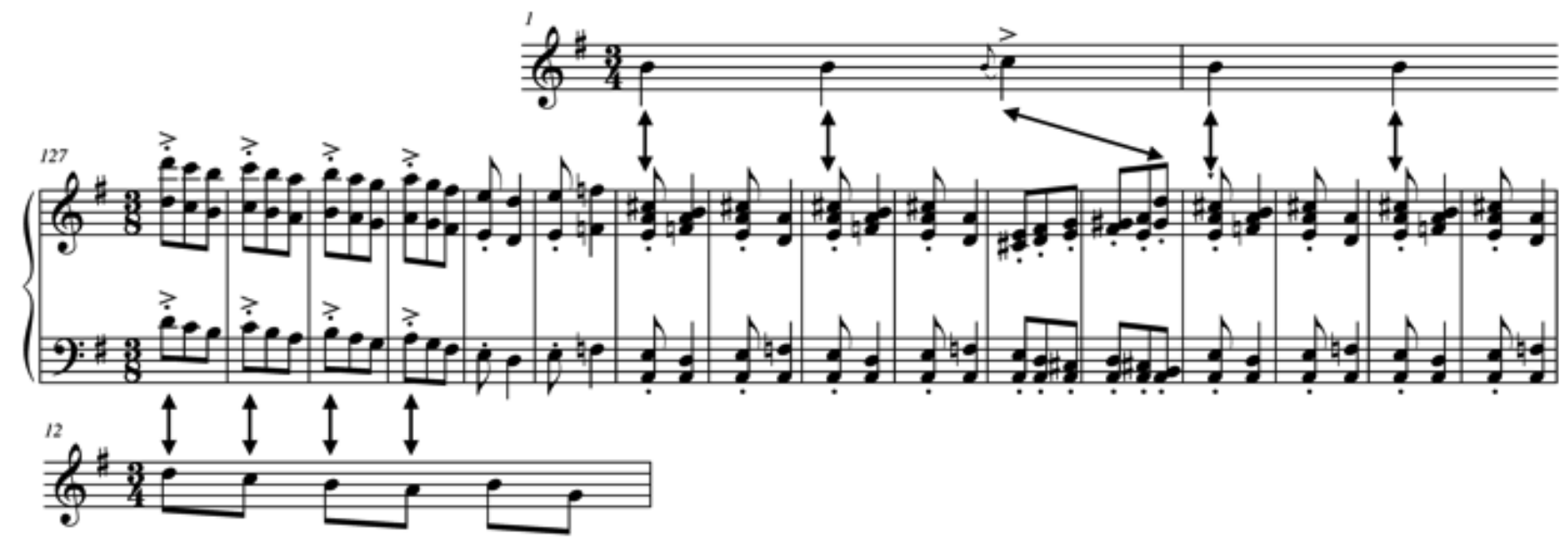

Example 6

Comparison of opening of C Presto with Allegretto motives 
Murphy, Scott. "Metric Cubes in Some Music of Brahms," Journal of Music Theory 53/1 (Spring, 2009): 1-56.

Publisher's official version http://dx.doi.org/10.1215/00222909-2009-020. Open Access version: http://hdl.handle.net/1808/9937.

a.

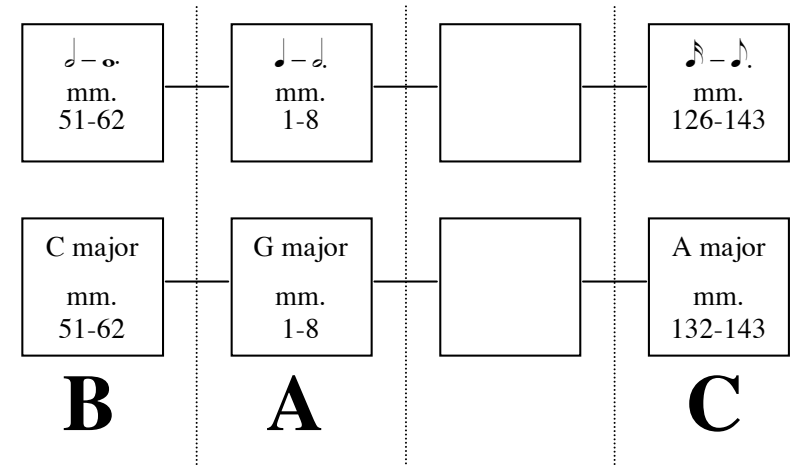

Figure 10

Comparison of a metric space with a segment of fifths 
Murphy, Scott. "Metric Cubes in Some Music of Brahms," Journal of Music Theory 53/1 (Spring, 2009): 1-56.

Pyblisher's official version http://dx.doi.org/10_7215/90̈222909;2009-020. _pen Access version: http://hdl.handle.net/1808/9937.
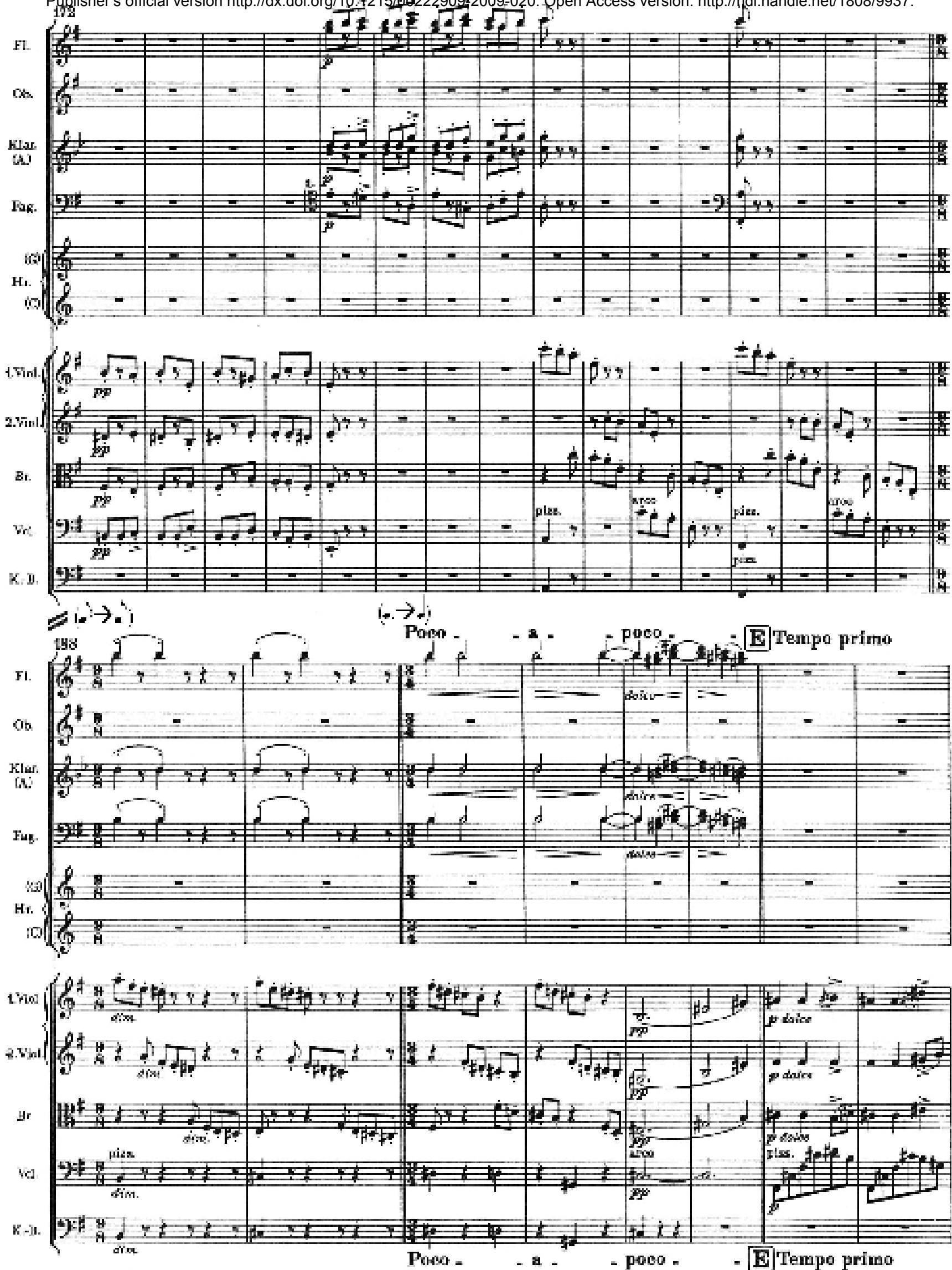

Example 7

Brahms, Second Symphony, first movement, mm. 172-95 
Murphy, Scott. "Metric Cubes in Some Music of Brahms," Journal of Music Theory 53/1 (Spring, 2009): 1-56.

Publisher's official version http://dx.doi.org/10.1215/00222909-2009-020. Open Access version: http://hdl.handle.net/1808/9937.
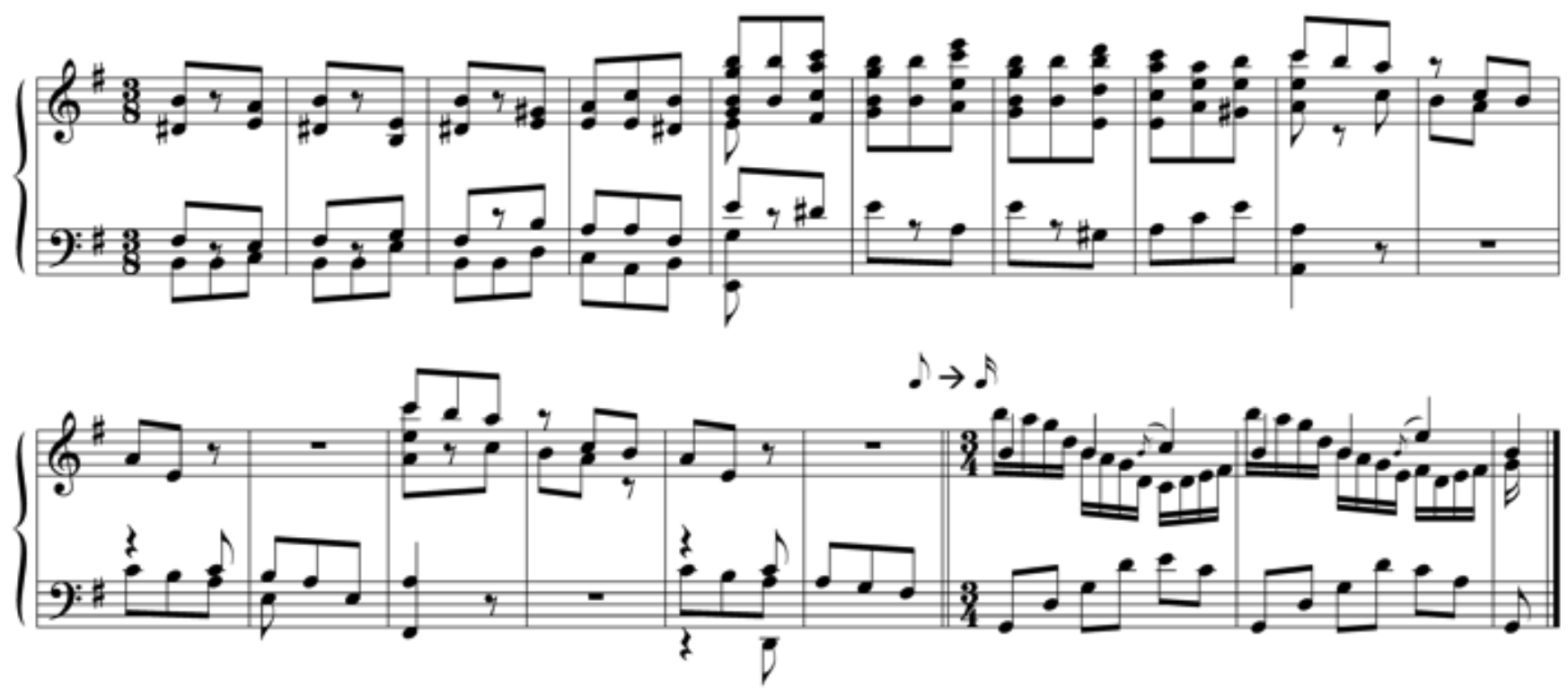

Example 8

Recomposition of retransition following mm. 180-87 
Murphy, Scott. "Metric Cubes in Some Music of Brahms," Journal of Music Theory 53/1 (Spring, 2009): 1-56.

Publisher's official version http://dx.doi.org/10.1215/00222909-2009-020. Open Access version: http://hdl.handle.net/1808/9937.

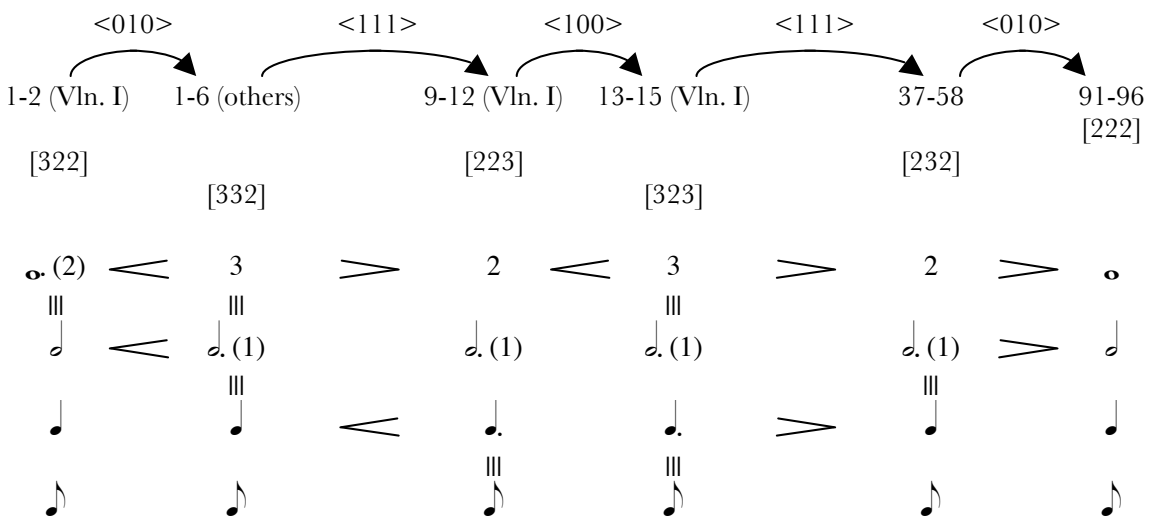

\section{Figure 11}

Succession of first appearances of 3-cube meters and intervening transformations in Brahms, Second String Quartet, fourth movement, with the eighth note as the common pulse 
Murphy, Scott. "Metric Cubes in Some Music of Brahms," Journal of Music Theory 53/1 (Spring, 2009): 1-56.

Publisher's offiçiallverșion http://dx.doi.org/10.1215/00222909-2009-020. Open Access version: http://hdl.handle.net/1808/9937.

Allegro non assai

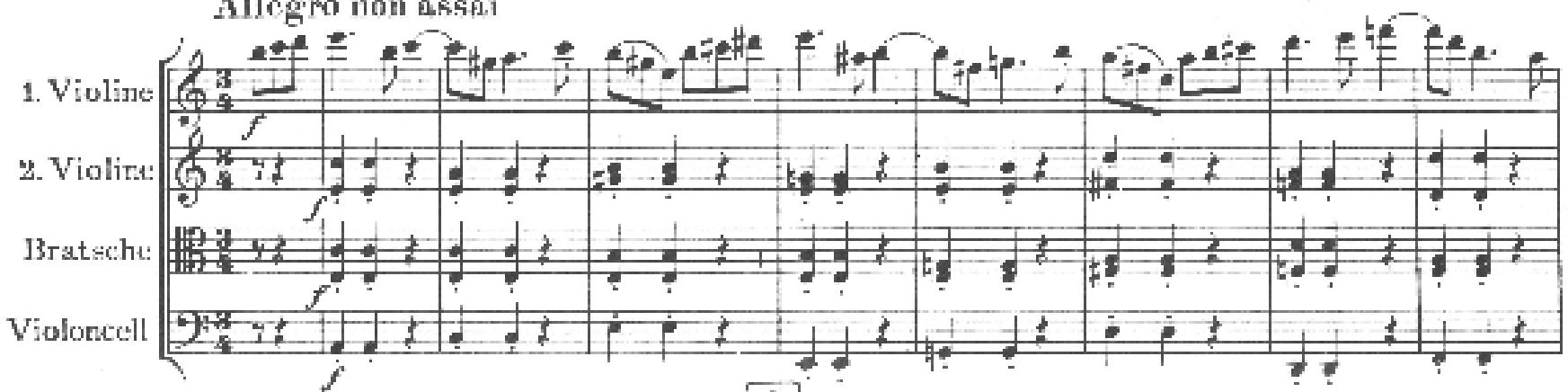

A

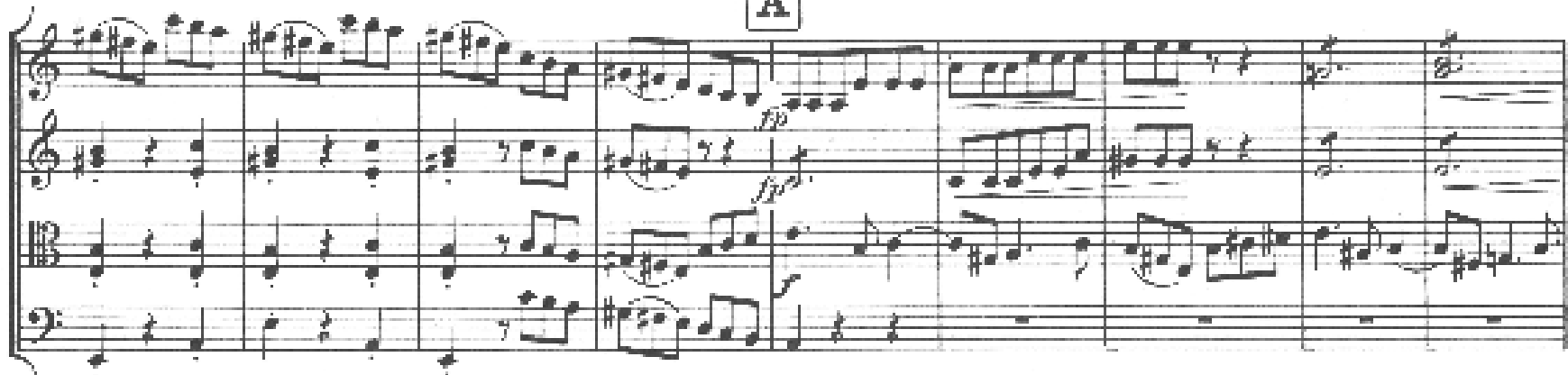

Example 9

Brahms, Second String Quartet, fourth movement, excerpts

Example 9a

Measures 1-17

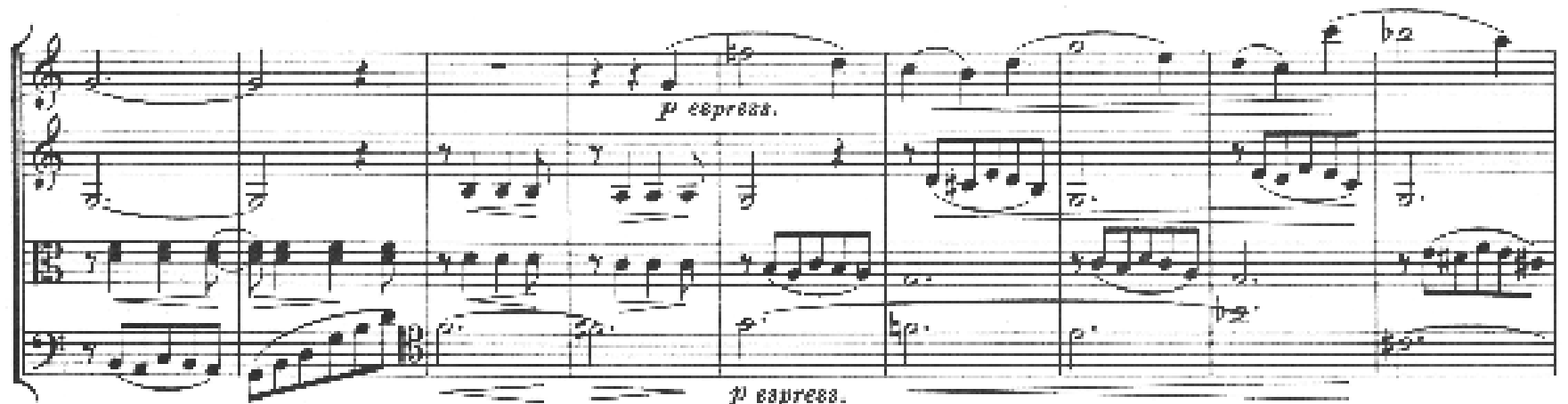

Example 9b

Measures 41-49 


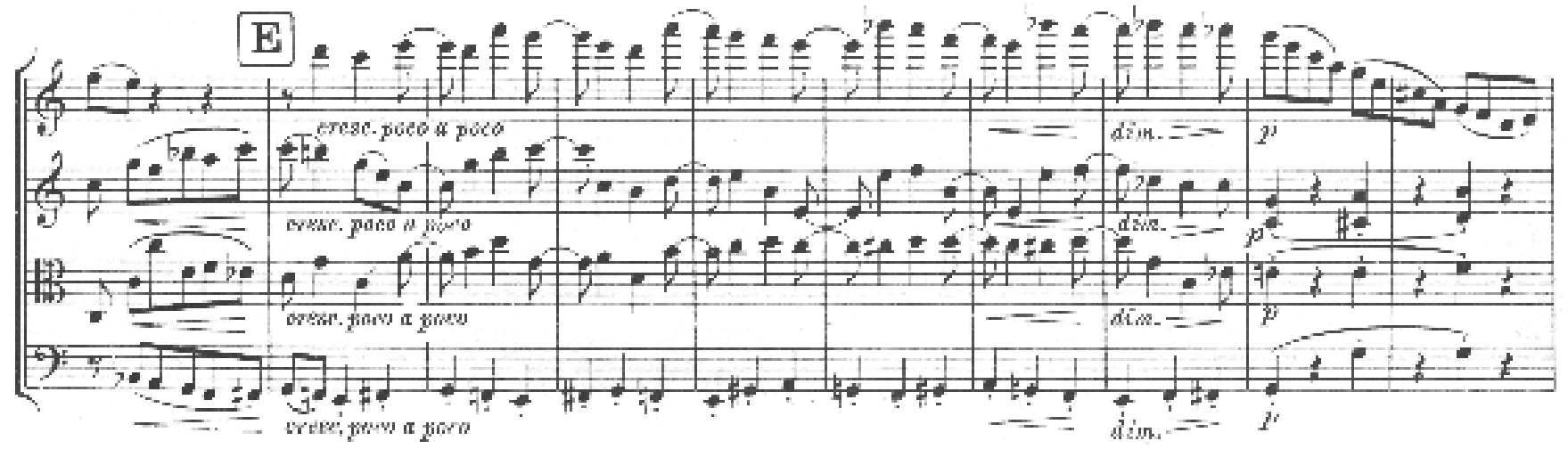

Example 9c

Measures 90-99

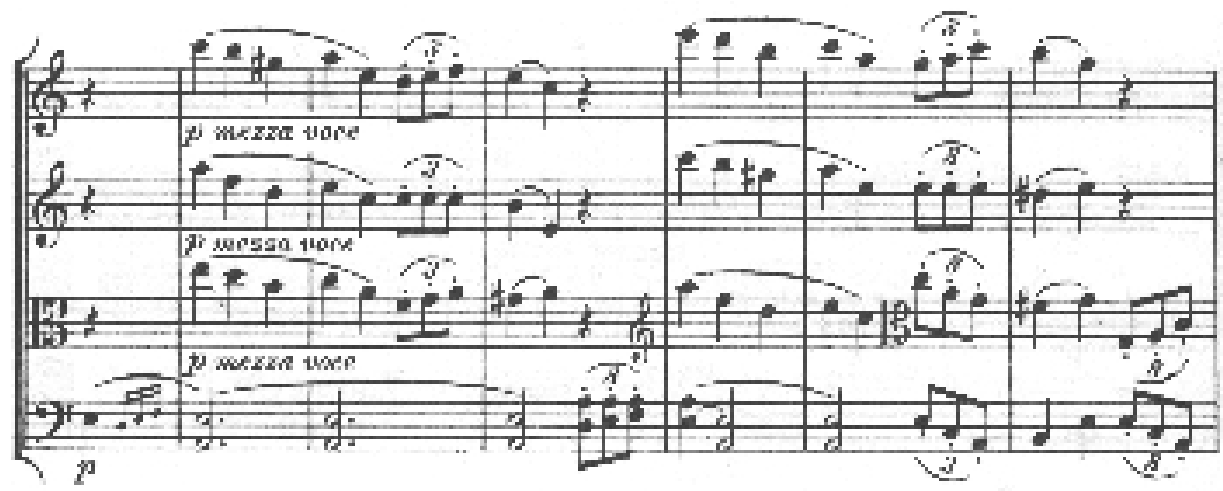

Example 10

Brahms, Second String Quartet, third movement, excerpts

Example 10a

Measures 134-39 
Murphy, Scott. "Metric Cubes in Some Music of Brahms," Journal of Music Theory 53/1 (Spring, 2009): 1-56.

Publisher's official version http://dx.doi.org/10.1215/00222909-2009-020. Open Access version: http://hdl.handle.net/1808/9937.

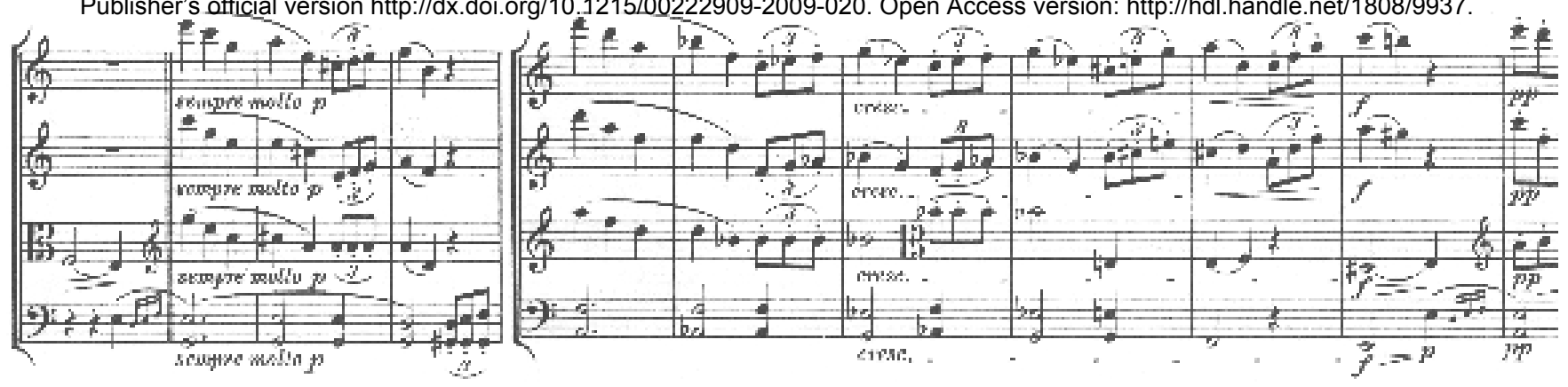

Example 10b

Measures 148-57 


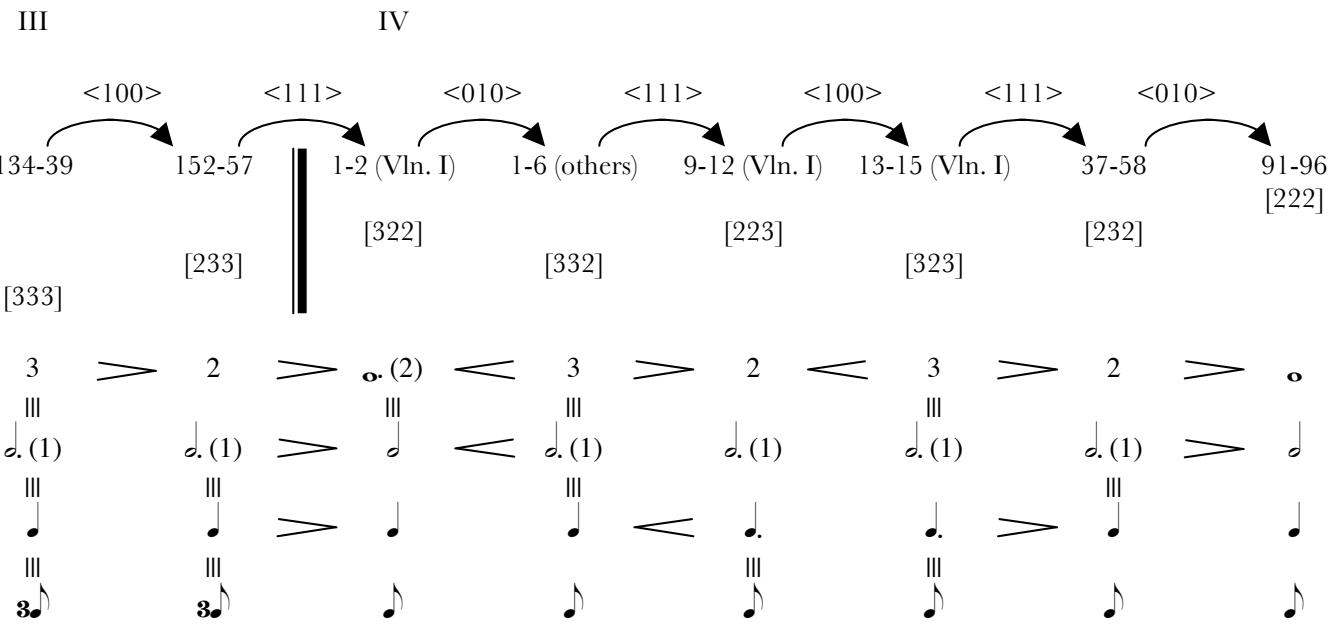

Figure 12. Succession of first appearances of 3-cube meters and intervening transformations in Brahms, Second String Quartet, end of the third movement and beginning of the fourth movement

Figure 12

Succession of first appearances of 3-cube meters and intervening transformations in Brahms, Second String Quartet, end of the third movement and beginning of the fourth movement 
Murphy, Scott. "Metric Cubes in Some Music of Brahms," Journal of Music Theory 53/1 (Spring, 2009): 1-56.

Publisher's official version http://dx.doi.org/10.1215/00222909-2009-020. Open Access version: http://hdl.handle.net/1808/9937.

\begin{tabular}{|c|c|c|c|c|c|c|c|c|}
\hline \multirow[t]{3}{*}{$\mathrm{R} 1$} & $1-25$ & $25-37$ & $37-44$ & $44-57$ & $58-71$ & $71-90$ & $91-100$ & $100-115$ \\
\hline & $P^{1.1}$ & $P^{1.2}$ & $\mathrm{TR}$ & $S^{1.1}$ & $S^{1.2}$ & $C^{1.1}$ & $C^{1.2}$ & RT \\
\hline & $\mathrm{Am}$ & $\mathrm{Am}$ & $\rightarrow \mathrm{CM}$ & $\mathrm{CM}$ & $\mathrm{CM}$ & $\mathrm{CM}$ & $\mathrm{CM}$ & $\rightarrow \mathrm{Am}$ \\
\hline \multirow[t]{3}{*}{ R2 } & 116-129 & $129-140$ & $140-143$ & 143-160 & \multicolumn{3}{|c|}{$161-173$} & 173-197 \\
\hline & & & TR & $S^{1.1}$ & \multicolumn{3}{|c|}{$\mathrm{S}^{1.2} \mathrm{dev}$} & \\
\hline & $\mathrm{Am}$ & $\rightarrow \mathrm{FM}$ & FM & FM & \multicolumn{3}{|c|}{$\rightarrow \mathrm{F}\{$ sharp $\} \mathrm{m}$} & $\rightarrow \mathrm{Am}$ \\
\hline \multirow[t]{3}{*}{ R3 } & $198-222$ & $222-234$ & $234-237$ & $238-250$ & 251-264 & $264-283$ & $284-293$ & \\
\hline & & & & & $\mathrm{S}^{1.2}$ & & $\mathrm{C}^{1.2}$ & \\
\hline & $\mathrm{Am}$ & $\mathrm{Am}$ & $\rightarrow \mathrm{AM}$ & $\mathrm{AM}$ & $\mathrm{AM}$ & $\mathrm{AM}$ & $\mathrm{AM}$ & \\
\hline \multirow[t]{5}{*}{ R4 } & $\begin{array}{l}293-333 \\
\mathrm{P}^{1.1}\end{array}$ & & & & & & & \\
\hline & $\mathrm{AM}$ & & & & & & & \\
\hline & $334-359$ & & & & & & & \\
\hline & $\mathrm{P}^{1.1}$ & & & & & & & \\
\hline & $\mathrm{Am}$ & & & & & & & \\
\hline
\end{tabular}

Figure 13

Formal outline of Brahms, Second String Quartet, fourth movement 
Murphy, Scott. "Metric Cubes in Some Music of Brahms," Journal of Music Theory 53/1 (Spring, 2009): 1-56.

Publisher's official version http://dx.doi.org/10.1215/00222909-2009-020. Open Access version: http://hdl.handle.net/1808/9937.

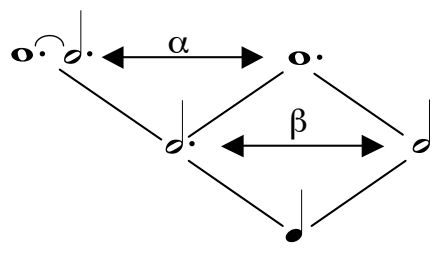

Figure 14a

A graph of pulses 
Murphy, Scott. "Metric Cubes in Some Music of Brahms," Journal of Music Theory 53/1 (Spring, 2009): 1-56.

Publisher's official version http://dx.doi.org/10.1215/00222909-2009-020. Open Access version: http://hdl.handle.net/1808/9937.

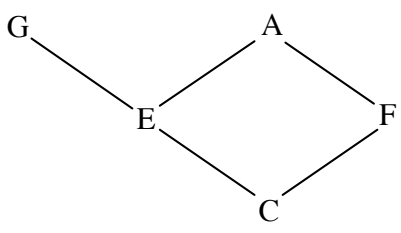

Figure $14 \mathrm{~b}$

A graph of diatonic pitch classes analogous to Figure 14a 
Murphy, Scott. "Metric Cubes in Some Music of Brahms," Journal of Music Theory 53/1 (Spring, 2009): 1-56.

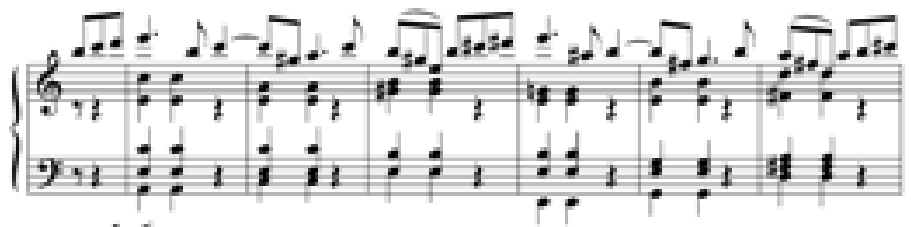

mm. 1-6
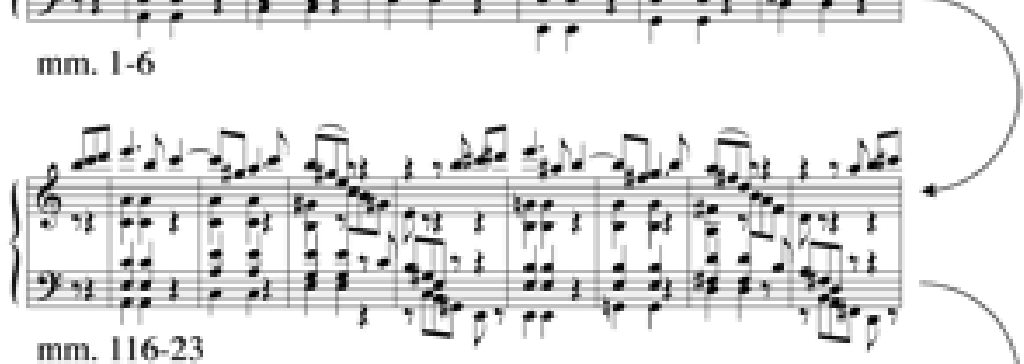

Change frow triple to duple and quadruple hypermeter through extension

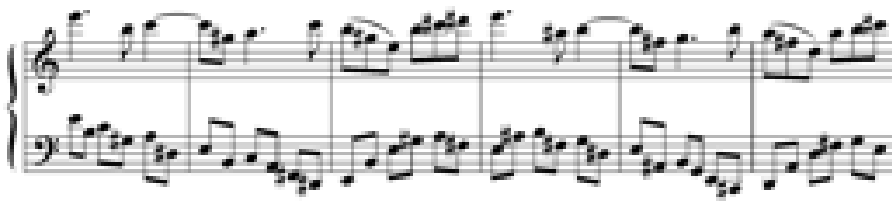

mm. 198-203 (outer voices only)

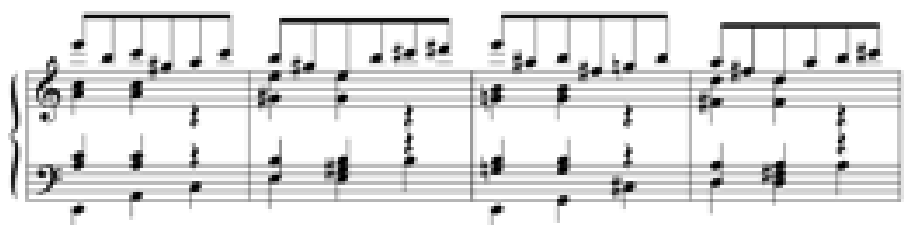

mm. $324-27$

Example 11

$\mathrm{P}^{1}$,s metric journey
Back to triple hypermeter: bass compresses theme's opening triadic descent into $3 / 4$

Melody of theme integrates previous bass compression into an uncontested $3 / 4$ meter and diple hypermeter 
Murphy, Scott. "Metric Cubes in Some Music of Brahms," Journal of Music Theory 53/1 (Spring, 2009): 1-56.

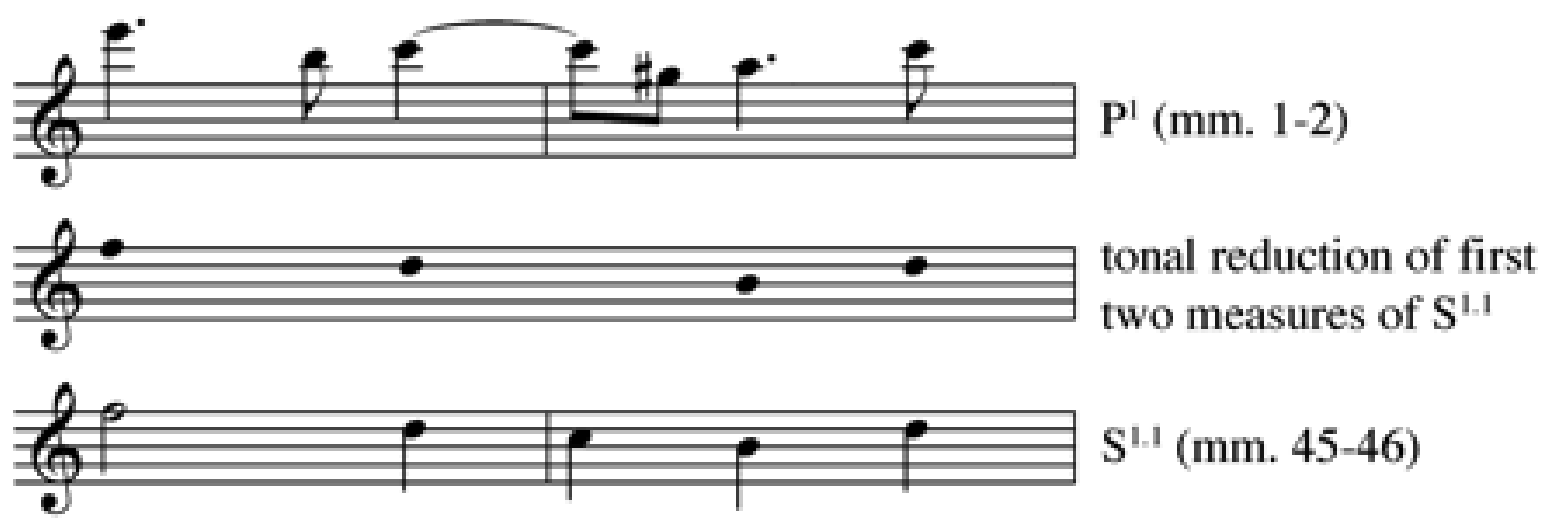

Example 12

Comparisons between opening measures of $\mathrm{P}^{1}$ and $\mathrm{S}^{1.1}$ themes

Example 12a

[no caption]

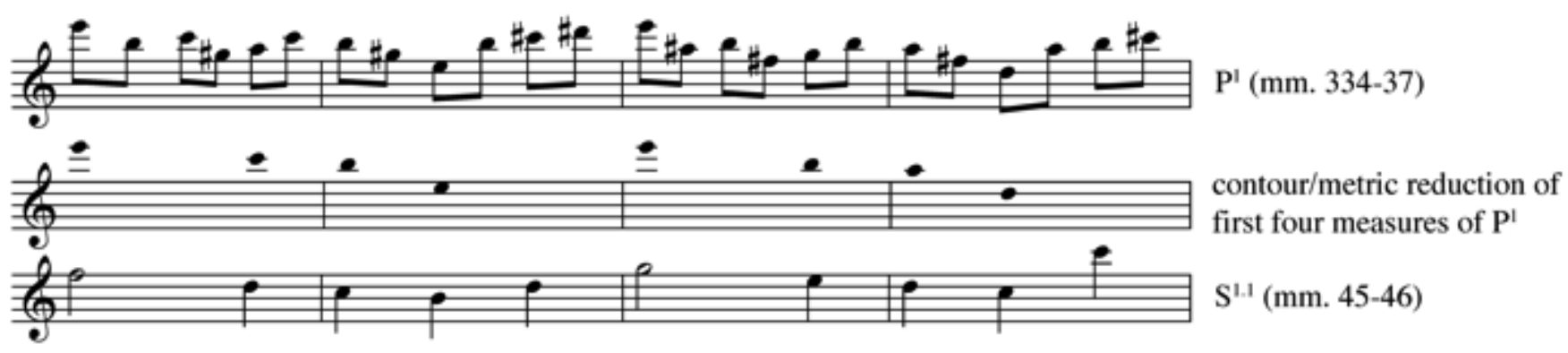

Example 12b

[no caption] 